\title{
Network Modulation of a Slow Intrinsic Oscillation of Cat Thalamocortical Neurons Implicated in Sleep Delta Waves: Cortically Induced Synchronization and Brainstem Cholinergic Suppression
}

\author{
M. Steriade, R. Curró Dossi, and A. Nuñez \\ Laboratoire de Neurophysiologie, Faculté de Médecine, Université Laval, Quebec, Canada G1K 7P4
}

A slow (0.5-4 Hz) oscillation of thalamic neurons was recently described and attributed to the interplay of two intrinsic currents. In this study, we investigated the network modulation of this intrinsic thalamic oscillation within the frequency range of EEG sleep $\delta$-waves. We performed intracellular and extracellular recordings of antidromically identified thalamocortical cells $(n=305)$ In sensory, motor, associational, and intralaminar nuclei of anesthetized cats.

At the resting membrane potential, $V_{m}(-60.3 \pm 0.4 \mathrm{mV}$, mean $\pm \mathrm{SE}$ ), cortical stimulation induced spindle-like oscillations $(7-14 \mathrm{~Hz})$, whereas at $V_{m}$ more negative than -65 $\mathrm{mV}$ the same stimuli triggered an oscillation within the EEG $\delta$-frequency $(0.5-4 \mathrm{~Hz})$, consisting of low-threshold spikes (LTSs) followed by afterhyperpolarizing potentials (AHPs). The LTS-AHP sequences outlasted cortical stimuli as a selfsustained rhythmicity at 1-2 Hz. Corticothalamic stimuli were able to transform subthreshold slow $(0.5-4 \mathrm{~Hz})$ oscillations, occurring spontaneously at $V_{m}$ more negative than $-65 \mathrm{mV}$, into rhythmic LTSs crowned by bursts of $\mathrm{Na}^{+}$spikes that persisted for 10-20 sec after cessation of cortical volleys. Cortical volleys also revived a hyperpolarization-activated slow oscillation when it dampened after a few cycles. Autoand crosscorrelograms of neuronal pairs revealed that unrelated cells became synchronized after a series of corticothalamic stimuli, with both neurons displaying rhythmic (1-2 Hz) bursts or spike trains. Since $\delta$-thalamic oscillations, prevailing during late sleep stages, are triggered at more negative $V_{m}$ than spindles characterizing the early sleep stage, we postulate a progressive hyperpolarization of thalamocortical neurons with the deepening of the behavioral state of EEG-synchronized sleep. In view of the evidence that cortical-elicited slow oscillations depend on synaptically induced hyperpolarization of thalamocortical cells, we propose that the potentiating influence of the corticothalamic input results from the engagement of two GABAergic thalamic cell classes, reticular and local-circuit neurons. The

\footnotetext{
Received Mar. 19, 1991; revised May 6, 1991; accepted May 23, 1991.

This work was supported by Medical Research Council of Canada Grant MT3689. R.C.D. is a postdoctoral fellow, on leave of absence from the University of Padova, Italy. A.N. is a postdoctoral fellow, on leave of absence from the Autonomous University of Madrid, Spain. We thank G. Oakson for providing the analysis software and P. Giguère and D. Drolet for technical assistance.

Correspondence should be addressed to Professor Dr. M. Steriade at the above address.

Copyright (C) 1991 Society for Neuroscience $0270-6474 / 91 / 113200-18 \$ 05.00 / 0$
}

thalamocorticothalamic loop would transfer the spike bursts of thalamic oscillating cells to cortical targets, which in turn would reinforce the oscillation by direct pathways and/or indirect projections relayed by reticular and local-circuit thalamic cells.

Stimulation of mesopontine cholinergic [peribrachial (PB) and laterodorsal tegmental (LDT)] nuclei in monoamine-depleted animals had an effect that was opposite to that exerted by corticothalamic volleys. PB/LDT stimulation reduced or suppressed the slow $(1-4 \mathrm{~Hz})$ oscillatory bursts of high-frequency spikes in thalamic cells. The PB/LDT effect was associated with depolarization of thalamocortical neurons and EEG activation. The cortical EEG response included the appearance of $\mathbf{4 0 ~} \mathrm{Hz}$ cortical waves. The short-lasting effect of PB/LDT stimulation lasted for 2-3 sec, was accompanied by increased membrane conductance, and was blocked by the nicotinic antagonist mecamylamine. Less often, the PB/LDT-induced disruption of the slow oscillation lasted for 10-15 sec. Similarly to the effect exerted by PB/ LDT stimulation, the slow oscillation of bursting neurons recorded from the dorsal lateral geniculate neurons was suppressed and replaced by tonic firing as a result of photic stimulation. Our results demonstrate that diffusely projecting modulatory systems or sensory-specific channels that succeed in depolarizing target thalamic cells decouple synchronized neurons, disrupt the slow oscillation, and prepare thalamocortical cells to transfer incoming signals.

These data indicate that, while the slow oscillation of individual thalamic neurons results from the interplay of their intrinsic currents, the synchronization of neuronal ensembles and, as a consequence, the genesis of macroscopic rhythmic EEG potentials, depend on the properties of thalamocortical networks including inhibitory thalamic cells. The suppression of $\delta$-oscillation with transition from slow-wave sleep to either arousal or rapid-eye-movement sleep is largely due to brainstem-thalamic cholinergic modulation acting diffusely on thalamocortical systems.

Two distinct types of EEG rhythms characterize the state of sleep with EEG synchronization: spindle oscillations $(7-14 \mathrm{~Hz})$ and $\delta$-waves $(0.5-4 \mathrm{~Hz})$. The former appear during drowsiness and early stages of sleep, while the latter predominantly occur during late sleep stages. It has been established that spindles originate in the thalamus since they are not abolished by decortication and brainstem transection (Morison and Bassett, 
1945). Spindlc oscillations depend on the intrinsic and network properties of reticular thalamic (RE) neurons, which impose cyclic IPSPs upon thalamocortical cells, followed by rebound bursts transferred to the cerebral cortex (Steriade et al., 1990c). The origin and cellular mechanisms of the other sleep rhythm, $\delta$-waves, have remained unknown. It was generally assumed, without sound evidence, that they exclusively originate in the cerebral cortex, and they were tentatively regarded as being generated by IPSPs as well as intrinsic long-lasting $\mathrm{K}^{+}$currents in cortical pyramidal cells (Steriade et al., 1990b). However, oscillations within the frequency range of $\delta$-waves have also been documented in the thalamus, with focal recordings in the ventrolateral (VL; Steriade et al., 1971) and RE (Steriade et al., 1987) nuclei.

Recent in vitro and in vivo studies have provided evidence for rhythmic $(0.5-4 \mathrm{~Hz})$ burst firing in thalamic neurons. A subpopulation of neurons recorded from dorsal lateral geniculate (dLG) thalamic slices displayed rhythmic bursts of highfrequency spikes with an interburst frequency of $1-2 \mathrm{~Hz}$ (McCormick and Pape, 1990a). This oscillation is believed to result from the interaction between the transient $\mathrm{Ca}^{2+}$ current $I_{i}$, underlying the low-threshold spike (LTS) (Deschênes et al., 1984; Jahnsen and Llinás, 1984a,b), and the hyperpolarization-activated cation current $I_{h}$ (McCormick and Pape, 1990a). The involvement of the LTS in this slow rhythm was also shown by the absence of the $1-2 \mathrm{~Hz}$ oscillation in thalamic cell types devoid of $I_{t}$ (Leresche et al., 1990). In vivo studies in this laboratory (Curró Dossi et al., 1991) have shown that an imposed hyperpolarization to membrane potential values characteristic for EEG-synchronized sleep leads identified cortical-projecting neurons in a variety of thalamic nuclei to an oscillation at $0.5-$ $4 \mathrm{~Hz}$. These studies also showed that the same type of oscillation occurs spontaneously when deafferentation procedures bring the $V_{m}$ negative to $-65 \mathrm{mV}$.

In this article we address two questions related to the synaptic modulation of the $0.5-4 \mathrm{~Hz}$ rhythmicity (hereafter termed slow or $\delta$-oscillation) generated by the intrinsic properties of thalamocortical neurons.

(1) Are slowly oscillating thalamic elements united into neuronal ensembles? Phase-locked activity in a number of oscillatory thalamocortical cells would make possible that $\delta$-waves occur as macroscopic EEG events, recordable with rather gross electrodes, as previously observed in VL and RE thalamic nuclei (see above). Since the $I_{h}-I_{t}$ interplay underlying the slow oscillation is dependent upon the hyperpolarization of thalamic neurons (McCormick and Pape, 1990a; Curró Dossi et al., 1991), the synchronizing candidates should be mainly searched for among network elements with inhibitory properties and widespread projections to dorsal thalamic nuclei. It is known that there is very little, if any, cross talk between dorsal thalamic nuclei and thalamocortical cells (Jones, 1985). Intrathalamic communication is provided by reciprocal projections between most dorsal thalamic nuclei and the GABAergic RE nuclear complex (Steriade et al., 1984). Another possible synchronizing device, confined to restricted territories within each thalamic nucleus, are GABAergic local-circuit neurons. Since $\delta$-waves are also generated in the cortex (Villablanca, 1974) and neocortical neurons have access to both RE and local-circuit cells (Jones, 1985), we asked whether synchronized thalamic activities may be entrained by resonant thalamocorticothalamic loops involving the two thalamic inhibitory cell types. We will show that setting into action corticofugal projections is indeed a powerful way to potentiate $\delta$-thalamic oscillations and to synchronize thalamocortical neurons within this slow frequency range.

(2) What are the modulatory systems that account for the suppression of $\delta$-rhythm with transition from EEG-synchronized sleep to either wakefulness or rapid-eye-movement (REM) sleep? We attempted to block the slow oscillation by stimulating mesopontine cholinergic aggregates, the peribrachial (PB) and laterodorsal tegmental (LDT) nuclei, taking into consideration that brainstem cholinergic neurons with identified thalamic projections increase their firing rates prior to EEG desynchronization upon arousal and REM sleep (Steriade et al., 1990a). Application of ACh in vitro (McCormick and Prince, 1987) and stimulation of brainstem cholinergic pathways in vivo (Curró Dossi et al., 1990) depolarize thalamocortical neurons through both nicotinic- and muscarinic-mediated mechanisms. We hypothesized that this action will bring thalamic cells out of the voltage range where the slow oscillation appears and will promote tonic firing characteristics for activated behavioral states.

\section{Materials and Methods}

Experiments were conducted on 41 adult cats under two different anesthetic conditions: urethane $(1.8 \mathrm{gm} / \mathrm{kg}$, i.p.); and ketamine $(40 \mathrm{mg} /$ $\mathrm{kg}$, i.m.) followed by a mixture of halothane and nitrous oxide. Under both conditions, cortical and brainstem cholinergic effects upon $\delta$-oscillations of thalamic cells were similar. Barbiturates were not used because (1) they prevent thalamocortical cells to display $\delta$-oscillations (Curró Dossi et al., 1991; Nuñez et al., 1991), and (2) they profoundly depress the cholinergic responses of thalamocortical cells (Eysel et al., 1986). In addition to the general anesthetics, all wounds and pressure points wcre infiltrated with lidocaine. The depth of anesthesia was continuously monitored to obtain an EEG-synchronized pattern similar to that observed during natural slow-wave sleep. The animals were paralyzed with gallamine triethiodide and artificially ventilated with control of the end-tidal $\mathrm{CO}_{2}$ concentration at $3.7 \pm 0.2 \%$. The body temperature was maintained at $38^{\circ} \mathrm{C}$.

To reduce synaptic noise and to avoid breaking of micropipette, the whole extent of suprasylvian and marginal gyri, white matter overlying the thalamus, and fornix were removed by suction in all animals. In 23 animals, the decortication also included the pericruciate, coronal, ectosylvian, and cingulate gyri to ascertain that brainstem PB/LDT effects on thalamic neurons were not due to circuitous projections involving corticothalamic pathways and to set thalamocortical cells in a continuous state of slow oscillation.

Intracellular recordings were obtained with micropipettes filled with a $3 \mathrm{M}$ solution of $\mathrm{K}$-acetate (DC resistance, $30-40 \mathrm{M} \Omega$ ). Stability of recording was insured by cisternal drainage and bilateral pneumothorax. A high-impedance amplifier with active bridge circuitry was used to record and inject current inside the cells. The signals were recorded on tape (pass-band: $\mathrm{DC}-9 \mathrm{kHz}$ ), and the recorded data were digitized at a rate of 20,000 samples/sec before analysis on computer. To record extracellularly two or more units simultaneously, we used low-impedance glass or metal microelectrodes; unit discharges were recorded along with focal slow waves. We made recordings in the following relay, associational, and intralaminar nuclei: ventroanterior (VA)-VL and ventroposterior (VP) complexes, dLG, lateroposterior (LP), and centrolateral-paracentral (CL-PC) intralaminar wing. The anterior thalamic (AT) nuclei were not explored because a parallel study in this laboratory demonstrated that, despite having both LTS and hyperpolarizationactivated cation current, AT cells do not generally display $\delta$-oscillations (Curró Dossi et al., 1991).

Stimulating electrodes were either coaxial (the tip, with a diameter of $40 \mu \mathrm{m}$, was $0.8 \mathrm{~mm}$ below the peripheral ring) or made from used tungsten microelectrodes with tips bared $0.2-0.4 \mathrm{~mm}$. An array of four to six electrodes was inserted into the depth of the pericruciate gyri to activate VA-VL and CL nuclei or in the internal capsule to have access also to other thalamic nuclei. Another array of electrodes was inserted at the mesopontine junction to cover both PB area and LDT nucleus. Cortical or internal capsule stimulation was usually delivered as single pulses (duration, $0.1-0.3 \mathrm{msec}$; intensity, $0.05-0.2 \mathrm{~mA}$ ); occasionally, two short-delayed ( $3 \mathrm{msec}$ ) pulses were applied. The brainstem PB/LDT aggregates were stimulated with brief pulse trains ( 30 shocks at 100 
Figure 1. Physiological identification of intracellularly recorded thalamocortical cells. $A-C$ are from three different neurons; stimuli are marked by arrowheads or dots. $A$, Fast-conducting VL cell, activated orthodromically by brachium conjunctivum (BC) stimulation ( $I$; EPSP latency, $1.3 \mathrm{msec}$ ) and backfired by a three-shock train to precruciate gyrus $(2 ;$ antidromic response latency, $0.8 \mathrm{mscc}$ ). $V_{m}$ was $62 \mathrm{mV} . B$, Slow-conducting $\mathrm{CL}$ cell projecting to precruciate gyrus (antidromic response latency, $2 \mathrm{msec}$ ). Collision of antidromic spike with a spontaneous discharge is shown at the right. $V_{m}$ was $-58 \mathrm{mV}$. $C 1$. Sequence of spindle waves $(7.5 \mathrm{~Hz})$ triggered in VL neuron by stimulation of postcruciate gyrus (antidromic response latency, $3.3 \mathrm{msec}$ ). Shown in 2 are absence of antidromic responses to five shocks delivered during biphasic IPSP elicited by cortical stimulus, and recovery of responses when IPSP declincd. $V_{m}$ is indicated in $C(-60 \mathrm{mV})$ and the following figures.
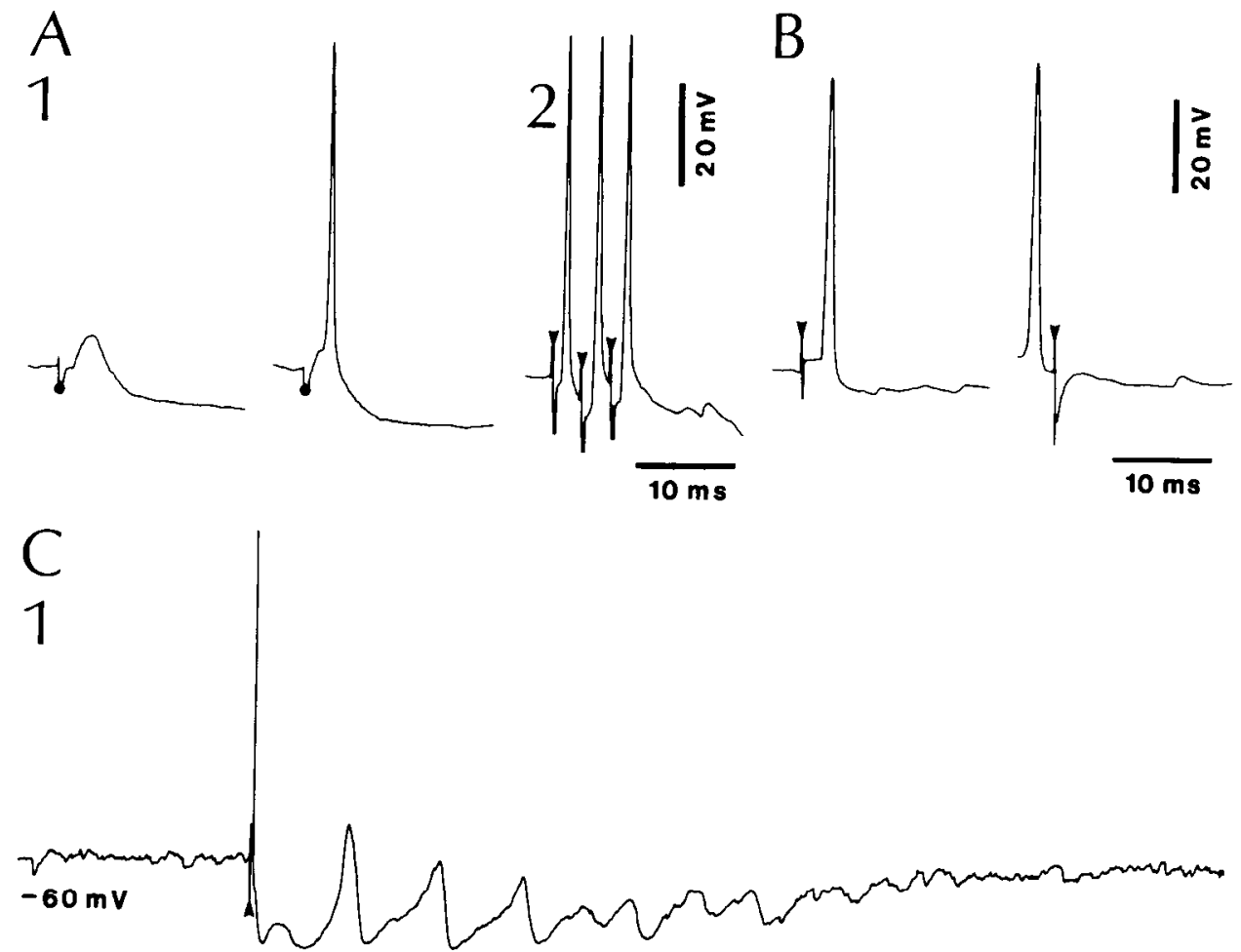

$10 \mathrm{~ms}$

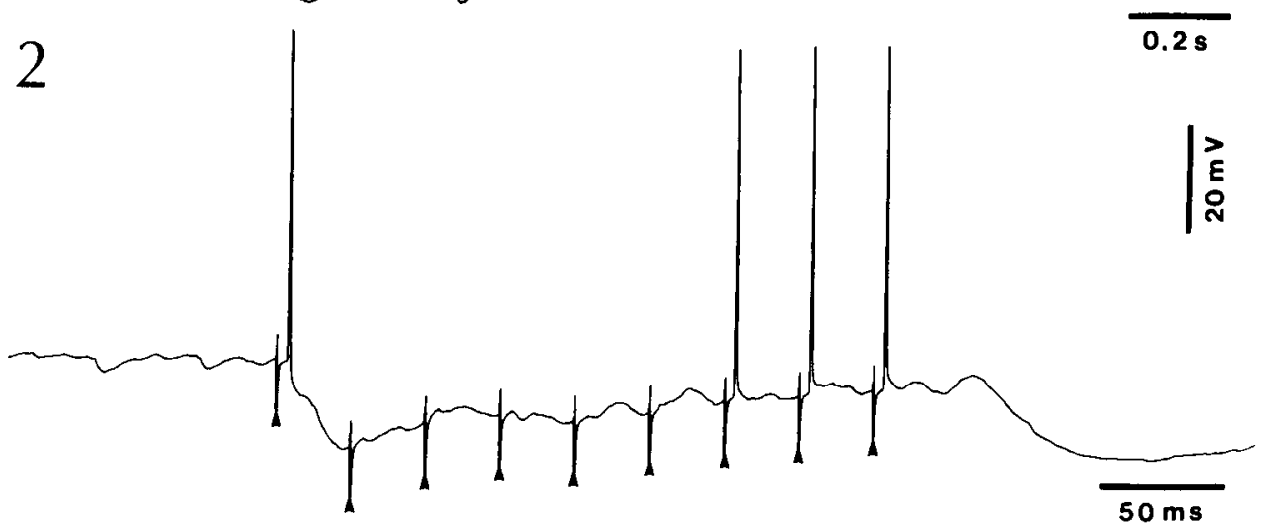

$300 \mathrm{~Hz}$ ); with longer trains $(1 \mathrm{sec})$ at the discharge rate $(30 \mathrm{~Hz})$ of $\mathrm{PB} /$ LDT neurons during behaviorally activated states (Steriade et al., 1990a); or with three to five pulse trains (each consisting of 10-30 shocks at $100-300 \mathrm{~Hz}$ ) that proved to be most effective in inducing long-lasting depolarization of thalamocortical neurons (Curró Dossi et al., 1991).

Twenty-eight VA-VL, LP, and CL-PC cells were recorded $24-48 \mathrm{hr}$ after reserpine treatment (Serpasil, 0.75-1 $\mathrm{mg} / \mathrm{kg}$ ) to prevent the effects of the coactivation of monoaminergic pathways. In reserpine-treated preparations, $\mathrm{PB} / \mathrm{LDT}$ effects were similar to those observed in the other animals. In 22 neurons, mecamylamine (40-60 $\mu \mathrm{g} / \mathrm{kg})$ and $/$ or scopolamine $(0.5-1 \mathrm{mg} / \mathrm{kg}$ ) was administered intravenously to antagonize the nicotinic and/or muscarinic responses to $\mathrm{PB} / \mathrm{LDT}$ stimulation. The effects of cholinergic antagonists were similar in reserpine-treated and in control animals.

At the end of experiments, the animals were deeply anesthetized with sodium pentobarbital $(50 \mathrm{mg} / \mathrm{kg}$ ) and perfused with 0.5 liter of $0.9 \%$ saline followed by 1 liter of $4 \%$ paraformaldehyde. The position of stimulating electrodes was verified on $80 \mu \mathrm{m}$ thionin-stained frontal sections.

\section{Results}

Data base, neuronal identification, and description of the slow cellular oscillation

We have recorded 128 cells intracellularly and 177 cells extracellularly; of the latter, 36 neurons were simultaneously recorded as couples or triples by the same microelectrode (see Figs. 8, 9, $11,13,17)$. The neurons recorded intracellularly had $V_{m}$ higher than $-55 \mathrm{mV}(60.3 \pm 0.4 \mathrm{mV}$, mean $\pm \mathrm{SE})$ and overshooting action potentials $(62.3 \pm 0.5 \mathrm{mV})$. Extracellularly recorded cells with discharges indicating signs of injury and axonal recordings (positive spikes shorter than $0.8 \mathrm{msec}$ ) were discarded.

Physiological identification of thalamocortical ncurons was achieved by antidromic invasion from the cerebral cortex or internal capsule and by monosynaptic excitation to stimulation of prethalamic pathways (Fig. 1). Criteria for antidromic identification were fixed latency, collision with a spontaneously occurring action potential, and, subsidiarily, ability to follow fast stimuli (Fig. 1 $A, B$ ). The latter criterion was not fulfilled when cortical stimulation induced a short-latency, prolonged inhibition in thalamic cells; faithful following of antidromic stimuli reappeared when the hyperpolarization declined (Fig. 1C). In intracellular recordings, the antidromic action potential was triggered directly from the resting membrane potential level (see Figs. $1 B, 5 B$ ). We observed a wide range of antidromic response latencies $(0.4-5 \mathrm{msec})$, reflecting various populations of thalamocortical cells with different conduction velocities. Since $\delta$-oscillations as well as their modulation by cortex and PB/LDT 


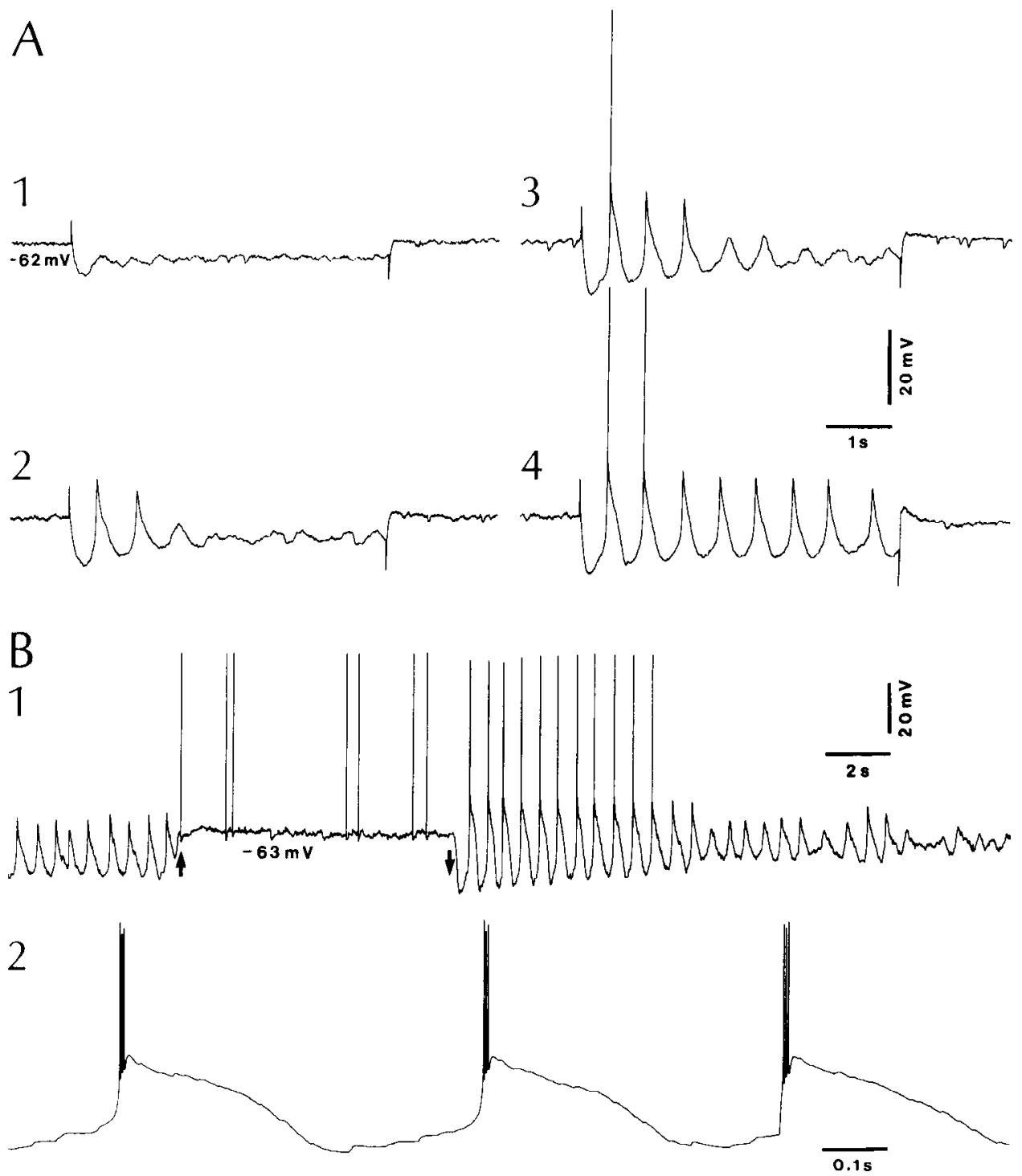

Figure 2. Slow oscillations of thalamocortical cells triggered by hyperpolarizing current pulses or occurring spontaneously. $A$, VL cell. Hyperpolarizing current pulses of $0.7 \mathrm{nA}(I), 1 \mathrm{nA}$ (2), $1.1 \mathrm{nA}(3)$, and $1.2 \mathrm{nA} \mathrm{(4)} \mathrm{elicited}$ an increasing number of cycles at 1.6 Hz. B, LP cell. At "rest," the cell oscillated spontaneously at $1.7 \mathrm{~Hz}$. A 0.5 nA depolarizing current (between arrows) prevented the oscillation, and its removal set the cell back in the oscillatory mode. Three cycles after removal of depolarizing current in 1 are expanded in 2 to show high-frequency spike bursts crowning LTSs. were present in identified thalamocortical cells regardless of variations in their antidromic response latencies, we will not take into consideration these differences. In addition to antidromic invasion, cortical or internal capsule stimulation evoked orthodromic response consisting of single spikes or doublets, with latencies compatible with monosynaptic excitation (see Fig. $8 A)$.

The oscillatory phenomena submitted to modulatory influences from the cerebral cortex and brainstem PB/LDT nuclei were $\delta$-oscillations induced by hyperpolarizing current pulses (Fig. $2 A$ ) or occurring spontaneously as a result of the membrane hyperpolarization after deafferentation procedures (Fig. $2 B$ ).

We found a correlation between the voltage deflection following injection of hyperpolarizing current pulses and the number of triggered cycles. Figure $2 A$ depicts such an experiment in which subthreshold oscillations at $2 \mathrm{~Hz}$ wcre cvoked in a VL cell by a small current pulse (Fig. $2 A 1$ ); overt oscillations progressively developed by injecting hyperpolarizing pulses with increasing intensities $(A 2-A 4)$. The oscillation consisted of rhythmic LTSs followed by afterhyperpolarizing potentials (AHPs). The intrinsic nature of the oscillation was demonstrated by the occurrence of rhythmic LTSs in isolation, without su- perimposed $\mathrm{Na}^{+}$spike bursts that could have synaptically engaged neurons in thalamic or cortical networks.

Neurons recorded from LP nucleus had $V_{m}$ from -65 to -76 $\mathrm{mV}$ and displayed oscillations without imposed current injections (Fig. 2B). In a parallel study (Curró Dossi et al., 1991), we discussed in detail this phenomenon and provided evidence that the high $V_{m}$ and associated spontaneous oscillations were due to the removal of a powerful depolarizing pressure originating from related cortical areas (suprasylvian and marginal gyri), a necessary procedure to avoid pipette breaking. The spontaneous oscillation of spike bursts was replaced by single spikes by applying steady depolarizing current. Removal of the depolarizing current set the cell back in the oscillatory mode (Fig. 2B1).

It should be emphasized that the actions of corticothalamic neurons vary with the behavioral state. Tonic depolarizing effects are exerted during waking when their single-spike discharges are sustained, whereas the high-frequency bursts of the same elements during EEG-synchronized sleep more effectively drive thalamic GABAergic neurons, thus producing an overwhelming hyperpolarization of thalamocortical cells (see next section and Discussion). 


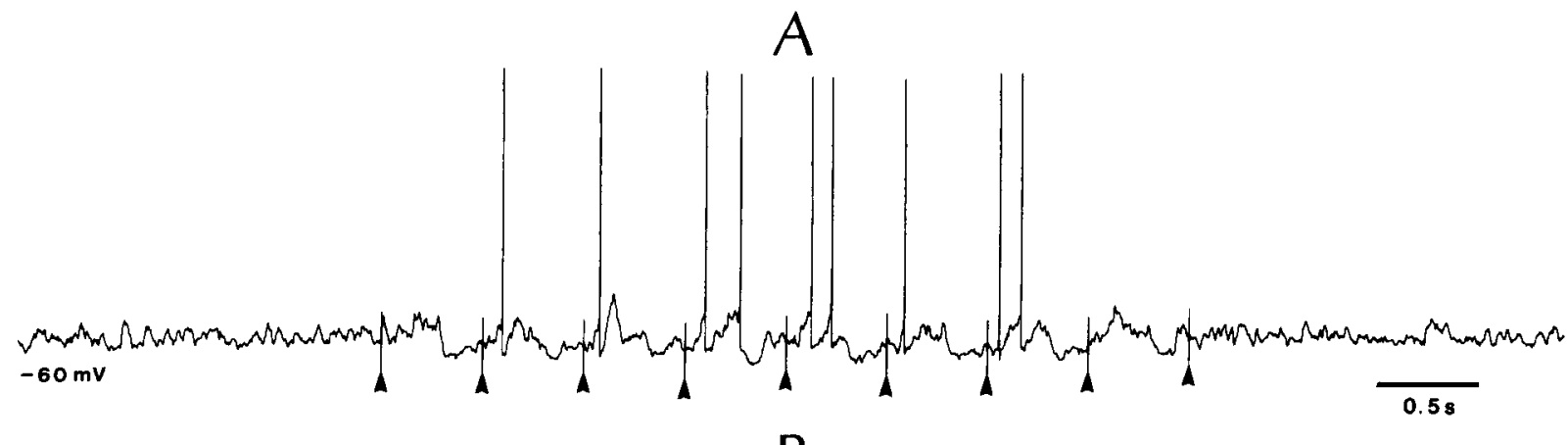

B

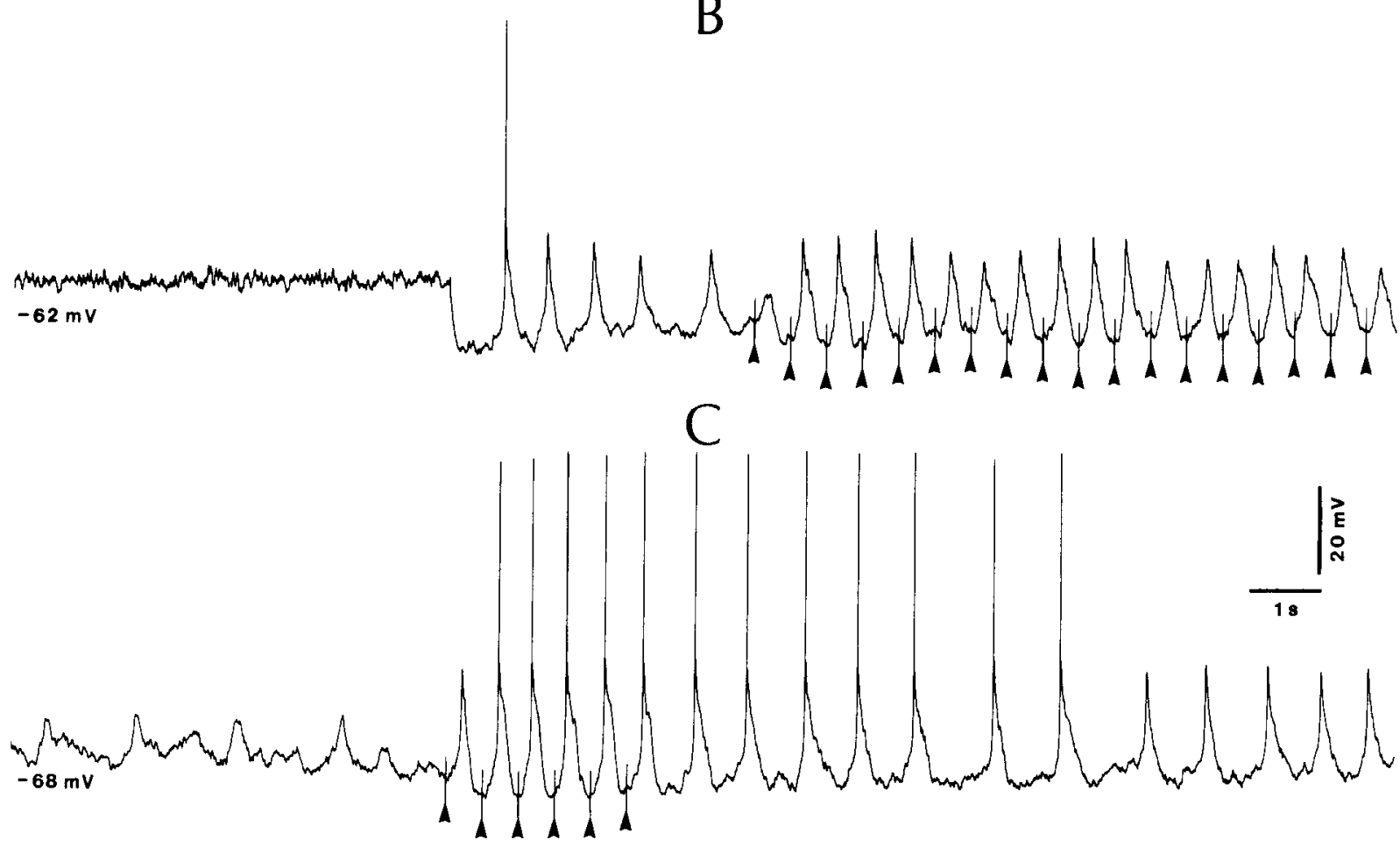

Figure 3. Cortical potentiation of slow oscillation in VL thalamocortical cell. $A$, At rest $(-60 \mathrm{mV})$, repetitive ( $2 \mathrm{~Hz})$ cortical stimuli (arrowheads) elicited EPSPs followed by secondary depolarizing responses. $B$. Hyperpolarization $(0.8 \mathrm{nA})$ bringing the $V_{m}$ from $-62 \mathrm{mV}$ to $-78 \mathrm{mV}$ induced a $2 \mathrm{~Hz}$ oscillation; when dampening of oscillation was imminent, cortical stimuli at $2 \mathrm{~Hz}$ (same parameters as in $A$ ) evoked LTSs. $C$, At $V_{m}$ of -68 $\mathrm{mV}$, a subthreshold oscillation at $0.8 \mathrm{~Hz}$ appeared; six cortical stimuli (same parameters as in $A$ and $B$ ) induced LTSs, and after cessation of stimuli, a self-sustained oscillation at $1-1.5 \mathrm{~Hz}$ ensued for $15 \mathrm{sec}$.
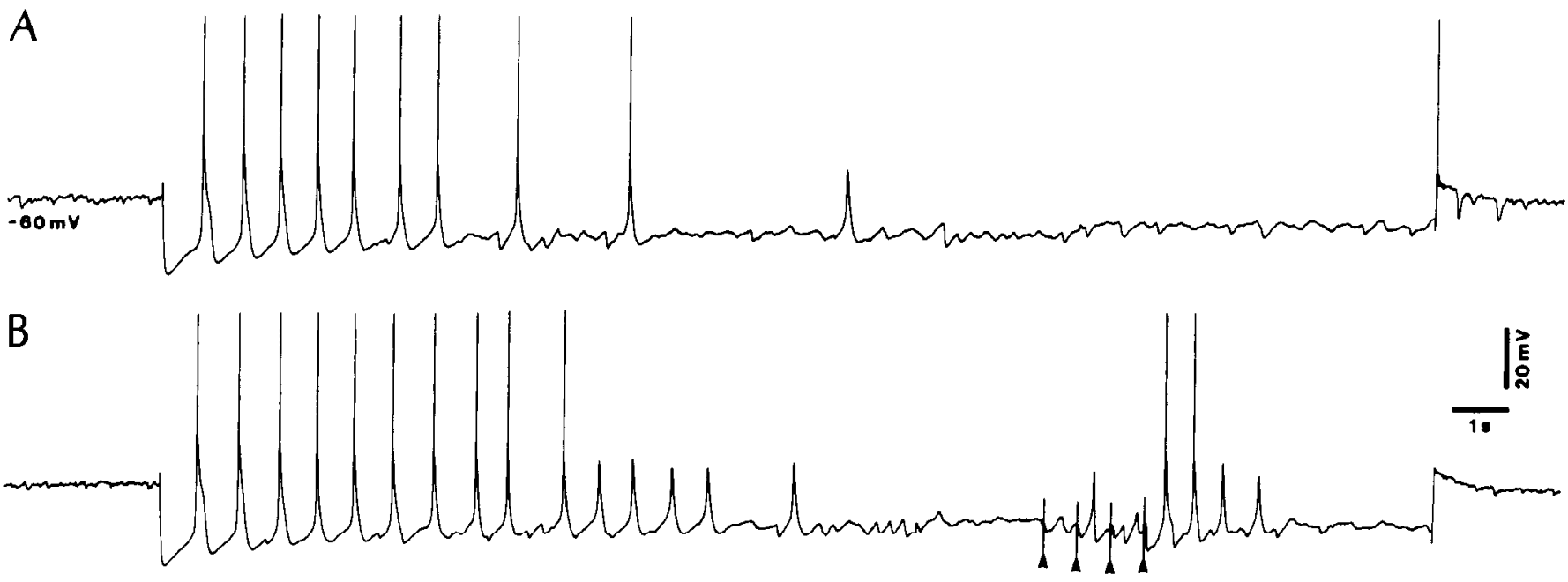

Figure 4. Cortical stimulation revives dampening slow oscillation (CL thalamocortical cell). Hyperpolarizing current pulses (duration, 22.5 sec; $0.9 \mathrm{nA}$ in $A, 1 \mathrm{nA}$ in $B$ ) elicited $1.4 \mathrm{~Hz}$ oscillation that dampened after $6 \sec (A)$ and $9 \mathrm{sec}(B)$. Four precruciate cortical stimuli $(B$, arrowheads) restarted self-sustained oscillation. 

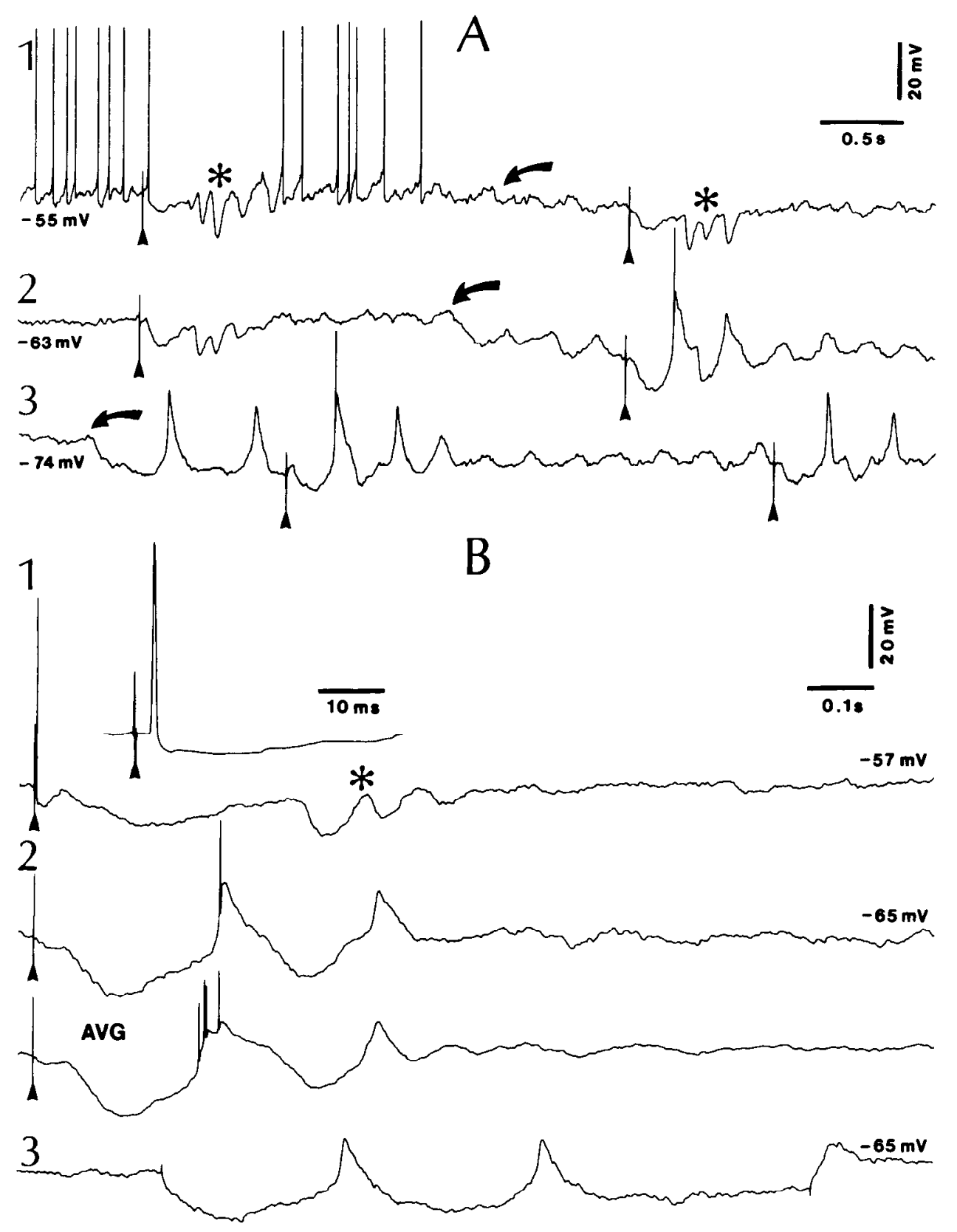

Figure 5. Cortical stimulation elicits spindles and $\delta$-waves at different $V_{m} . A$, VL thalamocortical cell. 1 , Cortical stimuli (arrowheads) elicited spindle waves at $8 \mathrm{~Hz}$ (marked by asterisks). DC hyperpolarization was applied at oblique arrow. 2, Further DC hyperpolarization (arrow) triggered a slow (3 $\mathrm{Hz}$ ) oscillation, and cortical stimulation enhanced this oscillation. 3, Further DC hyperpolarization (arrow). Note potentiating effect of subthreshold oscillation by second cortical stimulus (right arrowhead). B, CL thalamocortical cell. Inset, Antidromic invasion (2 msec latency). 1, Cortical-evoked spindles (asterisk) at rest $(-57 \mathrm{mV}) .2$, Cortical stimulus (same parameters as in 1 ) evoked slow oscillation at $-65 \mathrm{mV}$; $A V G$, Average of five traces. 3, Slow oscillation $(3.5 \mathrm{~Hz})$ by injecting a hyperpolarizing current pulse $(0.9 \mathrm{nA})$ at $-65 \mathrm{mV}$; note similarity with cortical evoked slow oscillation in 2 .

Potentiation of slow oscillations by cortical stimulation and corticothalamic synchronizing effects

Cortical stimulation influenced thalamic cells as a function of their $V_{m}$. At rest ( -55 to $-65 \mathrm{mV}$ ), single shocks elicited an EPSP occasionally crowned by action potential, while repetitive stimuli at $\geq 2 \mathrm{~Hz}$ evoked an augmented response characterized by the appearance of a sccondary depolarization and spike discharges (Fig. $3 A$ ). At $V_{m}$ more negative than $-68 \mathrm{mV}$, cortical stimuli elicited LTSs resembling those constituting the slow oscillation induced by a hyperpolarizing current pulse (Fig. $3 B$ ). When a subthreshold oscillation was present during DC hyper- polarization, cortical stimuli induced LTS-AHP sequences that outlasted the stimulation for $15 \mathrm{sec}$, with a self-sustained rhythm at $1-1.5 \mathrm{~Hz}$ (Fig. 3C).

Cortical stimuli were able to revive the hyperpolarizationtriggered slow oscillation, once it began to dampen $(n=16)$. Figure 4 depicts such a neuron in which a $1.4 \mathrm{~Hz}$ oscillation, induced during a hyperpolarizing step from the resting level $(-60 \mathrm{mV})$ to $-80 \mathrm{mV}$, lasted for $5-10 \mathrm{sec}$ and thereafter progressively disappeared. A few cortical stimuli at $\approx 2 \mathrm{~Hz}$ were applied, and self-sustained rhythmic LTSs, with and without spikes, outlasted the stimuli (Fig. $4 B$ ).

Two different types of rhythms were induced by cortical stim- 
Figure 6. Slow rhythm of hyperpolarization-rebound sequences (VP thalamocortical cell). $A$, At rest $(-55 \mathrm{mV})$, stimulation of the postcruciate gyrus (arrowhead) elicited a spindle sequence $(7 \mathrm{~Hz})$. DC hyperpolarization in two steps (oblique arrow) led to an LTS crowned by fast spike and, thereafter, a series of phasic hyperpolarization at 1$1.5 \mathrm{~Hz}$, usually followed by tiny LTSs; phasic hyperpolarization without LTS is seen after the three cycles elicited by cortical stimulus. $B$, Continued trace at $-68 \mathrm{mV}$. In both $A$ and $B$, cortical stimuli enhanced the slow oscillation and increased its frequency to $3 \mathrm{~Hz}$.
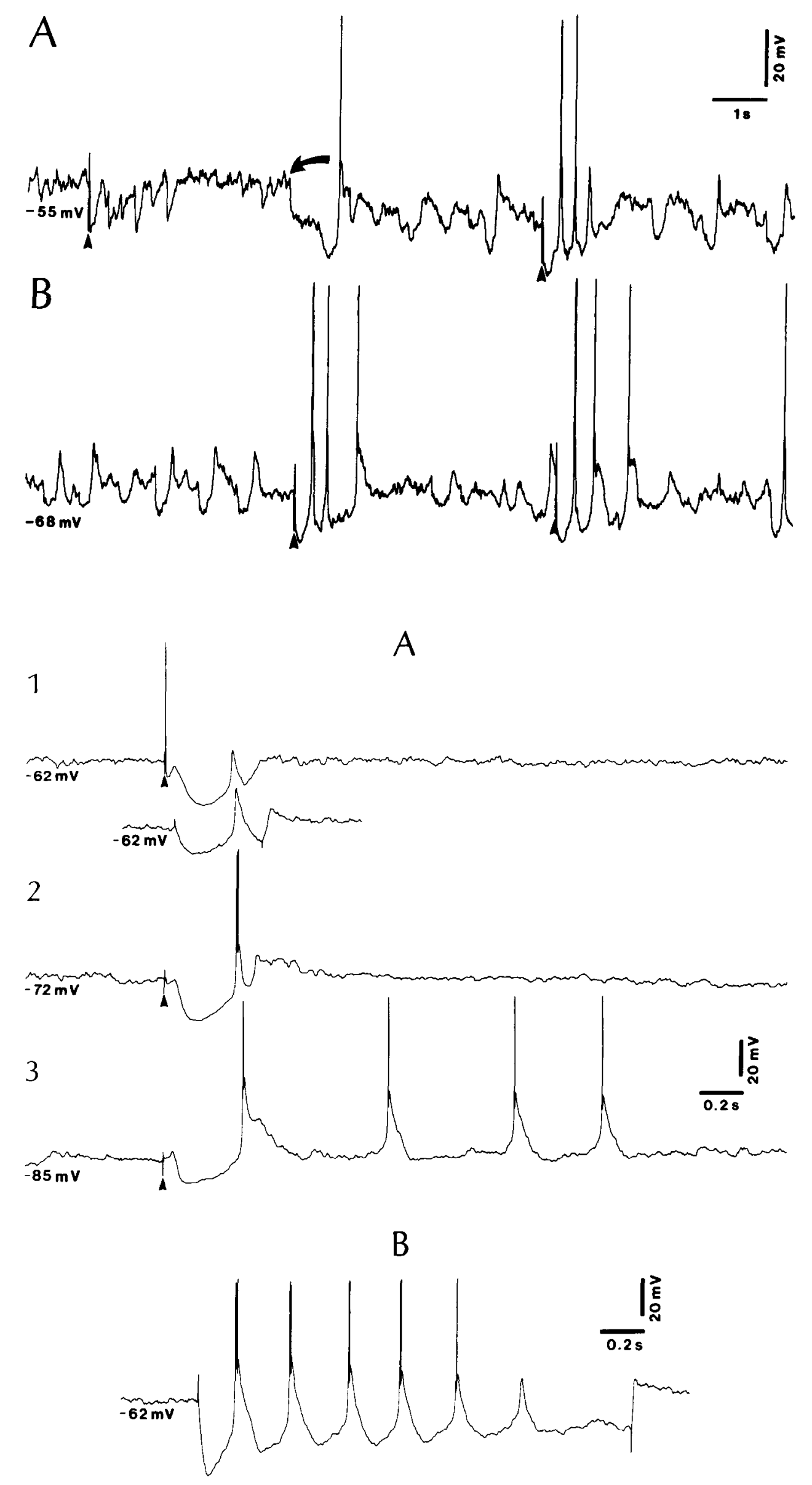

Figure 7. Cortical-evoked IPSP leads to slow oscillation (VA thalamocortical cell). Precruciate cortical stimuli are indicated by arrowheads. $A 1$, At rest ( -62 $\mathrm{mV}$ ) cortical stimulus elicited antidromic invasion, followed by IPSP and LTS. Below, a hyperpolarizing current pulse $(0.7 \mathrm{nA})$, aligned to start at the onset of the above cortical-evoked IPSP, is depicted to show similarity of LTS latency. 2, At $-72 \mathrm{mV}$, cortical stimulus with the same parameters as in $I$ elicited LTS crowned by high-frequency spike burst. 3 , At $-85 \mathrm{mV}$, cortical stimulus with same parameters elicited (after the IPSP-LTS sequence) a selfsustained oscillation at about $2 \mathrm{~Hz}, B$, In same neuron, hyperpolarizing current pulse ( $2 \mathrm{nA})$, bringing $V_{m}$ close to the level reached in $A 3$ by applying a cortical stimulus, clicited a slow oscillation with a quite different frequency $(4 \mathrm{~Hz})$ than in $A 3$. 

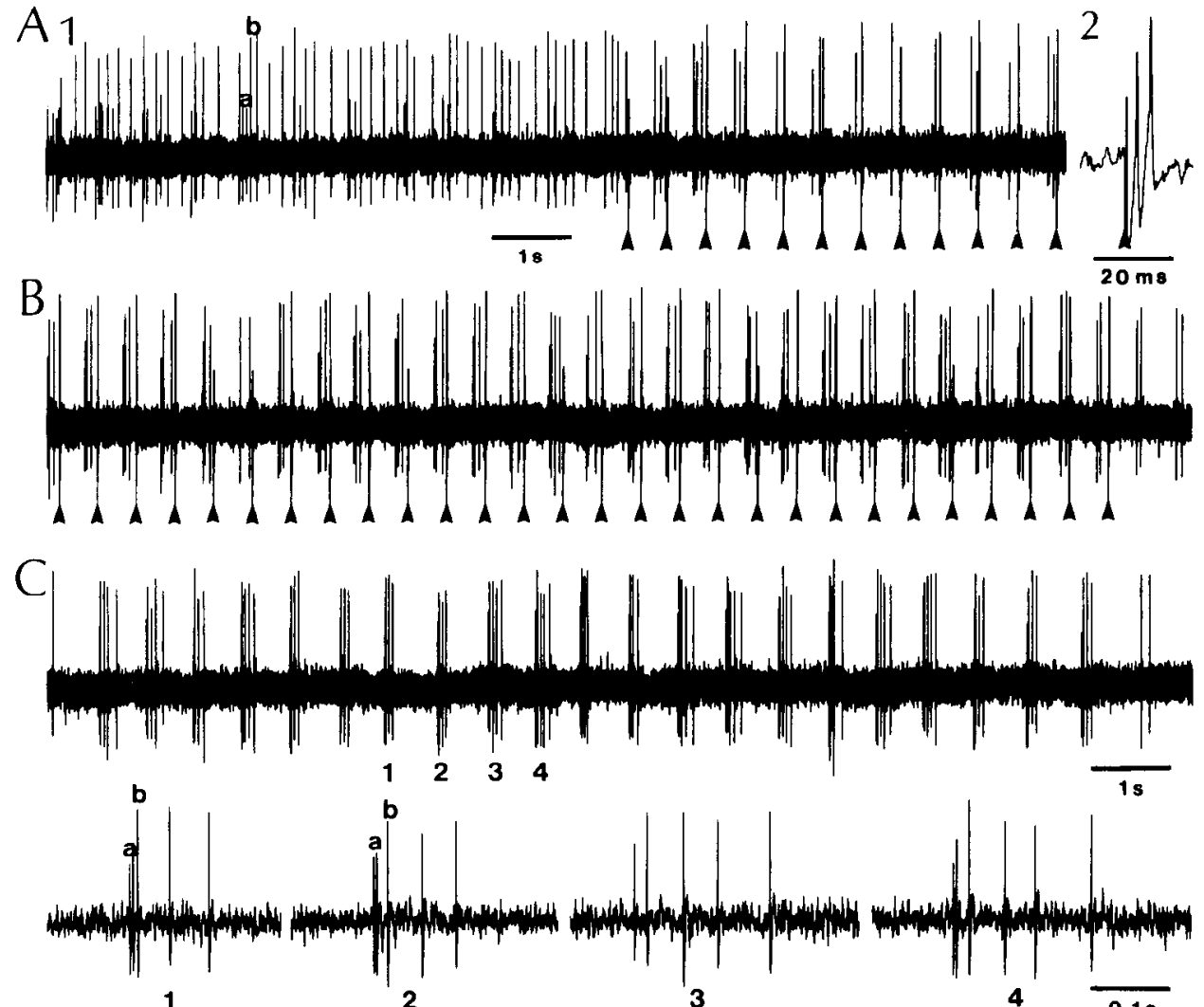

1
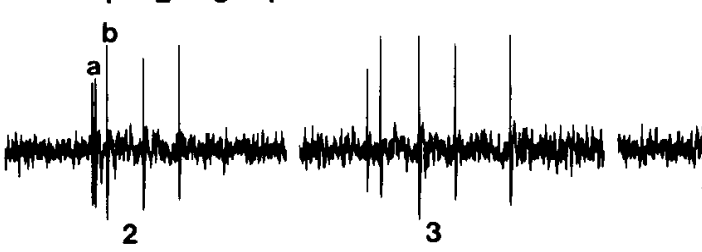

Figure 8. Cortical stimulation leads to self-sustained slow oscillation and synchronizes two simultaneously recorded VL thalamic cells. $A l$, Discharges before and during the initial period of postcruciate cortical stimuli (arrowheads). Note, before cortical stimulation, burst discharges of cell with small spike $(a)$ and tonic discharges of cell with large spike $(b)$. 2, Monosynaptic activation of cell $b$ by cortical stimulus. $B$ and $C$, Uninterrupted traces. After cessation of cortical stimulation that lasted for $30 \mathrm{sec}$, both cells were synchronized, with bursts of cell $a$ preceding single-spike trains of cell $b$. Epochs $1-4$ in upper trace of $C$ are expanded in lower trace. See Figure 9 for quantitative analyses of these neurons. ulation at different $V_{m}$ of thalamocortical cells: spindles and $\delta$-waves $(n=22)$. This phenomenon is depicted for two neurons in Figure 5. Panel $A$ illustrates a VL cell in which a precruciate cortical stimulus (at $V_{m}$ between -55 and $-63 \mathrm{mV}$ ) induced a hyperpolarization followed by a few cycles of oscillations in the spindling range $(8 \mathrm{~Hz}$ ). During steady hyperpolarization (to -70 to $-74 \mathrm{mV}$ ), spontaneous subthreshold $\delta$-oscillations at $2.5-3.5$ $\mathrm{Hz}$ appeared, and cortical stimulation enhanced the background oscillation. The other thalamocortical cell (Fig. 5B) displayed at rest, following the antidromic response, a long period of hyperpolarization and several spindle-like waves at $9 \mathrm{~Hz}$ (Fig. $5 B 1)$. Under DC hypcrpolarization, cortical stimulation induced an oscillation at $3.5-4 \mathrm{~Hz}$ (Fig. 5B2). A similar slow oscillation was triggered by a hyperpolarizing current pulse (Fig. $5 B 3)$.

In a few neurons $(n=5)$ that displayed the same development from cortical-evoked spindling to cortical-evoked $\delta$-oscillations by imposed changes in the $V_{m}$, the background cellular activity under DC hyperpolarization was characterized by a slow (1-1.5 $\mathrm{Hz}$ ) oscillation whose major component was a stereotyped, phasic hyperpolarizing potential lasting for about $220 \mathrm{msec}$ (Fig. 6). Most of these potentials gave rise to postinhibitory rebound LTSs; occasionally, however, phasic hyperpolarizations with smaller amplitudes occurred in isolation, without being followed by LTSs. We interpret these hyperpolarizing events as IPSPs induced in thalamocortical cells by either local-circuit or RE thalamic neurons, activated through thalamocorticothalamic loops and helping to synchronize slow oscillations in groups of thalamic relay cells (see Discussion).

Cortical-evoked long-lasting IPSPs could initiate a few selfsustained cycles within the frequency range of $\delta$-rhythm $(n=$ 12). The different frequency of this oscillation, compared to that induced in the same neuron by a hyperpolarizing pulse, suggests that the rhythmicity following the cortical-induced IPSP-rebound sequence probably set into action thalamocortical and corticothalamic networks, as opposed to the intrinsic nature of the hyperpolarization-generated slow oscillation. This is illustrated in Figure 7. At rest, the cortical-evoked IPSP consisted of two distinct components: the first phase diminished and thereafter reversed in polarity between -72 and $-85 \mathrm{mV}$, thus suggesting its $\mathrm{Cl}^{-}$dependency, whereas the second component had a much longer duration and its amplitude decreased at $V_{m}$ more negative than $-90 \mathrm{mV}$, suggestive of its mediation by $\mathrm{K}^{+}$ channels (Fig. 7/A). When a hyperpolarizing current pulse was injected to match the amplitude and duration of the second phase of the cortical-evoked IPSP, the subsequent LTS was similar in both cases (Fig. 7 Al). Under DC hyperpolarization bringing the $V_{m}$ to $-85 \mathrm{mV}$, the IPSP-LTS sequence was followed by a few oscillatory cycles at $2 \mathrm{~Hz}$. This frequency was quite different from that $(4 \mathrm{~Hz})$ of the slow oscillation triggered by a hyperpolarizing current pulse (Fig. 7B).

The synchronizing effect of cortical stimulation could be assessed with simultaneous recordings of two or three cells ( $n=$ 36). Most often, simultaneously recorded neurons did not fire in close time relation (but see Figs. 13, 17). Apparently, each element had its peculiar frequency of rhythmic spike bursts (between 0.5 and $4 \mathrm{~Hz}$ ) or discharged tonically. The spontaneous activity of two cells, unrelated before cortical stimulation, is depicted in Figure $8 \mathrm{~A}$. The absence of relation between the discharge of these two cells prior to cortical stimulation was confirmed by a crosscorrelogram analysis (Fig. 9). Single cortical shocks delivered at $2 \mathrm{~Hz}$ induced a period of inhibition of about $200 \mathrm{msec}$ in both neurons, and after $30 \mathrm{sec}$ of cortical stimulation, the two cells became clearly coupled (Fig. 8B,C). Au- 

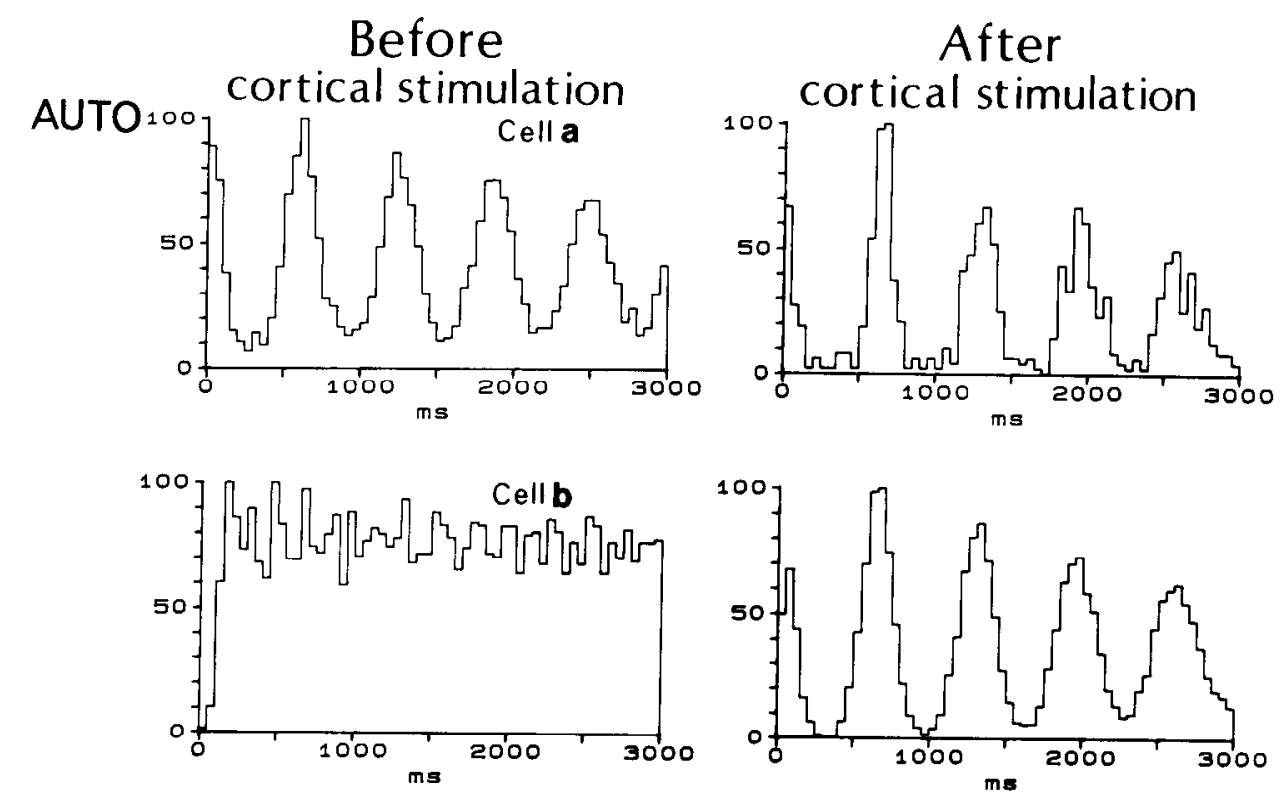

Figure 9. Auto- and crosscorrelograms of two cells ( $a$ and $b$ ), recorded simultaneously in VL nucleus (same cells as in Fig. 8). Four correlograms (before and cortical stimulation) depict, from top to bottom, autocorrelogram of cell $a$, autocorrelogram of cell $b$, and crosscorrelogram of both cells (cell $b$ is the reference cell) with two different bins ( 2 and $20 \mathrm{msec}$ ). Note, before cortical stimulation, slow $(1.6 \mathrm{~Hz})$ rhythm of cell $a$, flat contour (absence of rhythmicity) in cell $b$, and absence of coupling between these neurons. After cortical stimulation, the background noise in cell $a$ was reduced, cell $b$ became rhythmic at the same frequency as cell $a(1.6 \mathrm{~Hz})$, and crosscorrelograms show that cell $a$ firing preceded cell $b$ firing by about $10-20 \mathrm{msec}$.
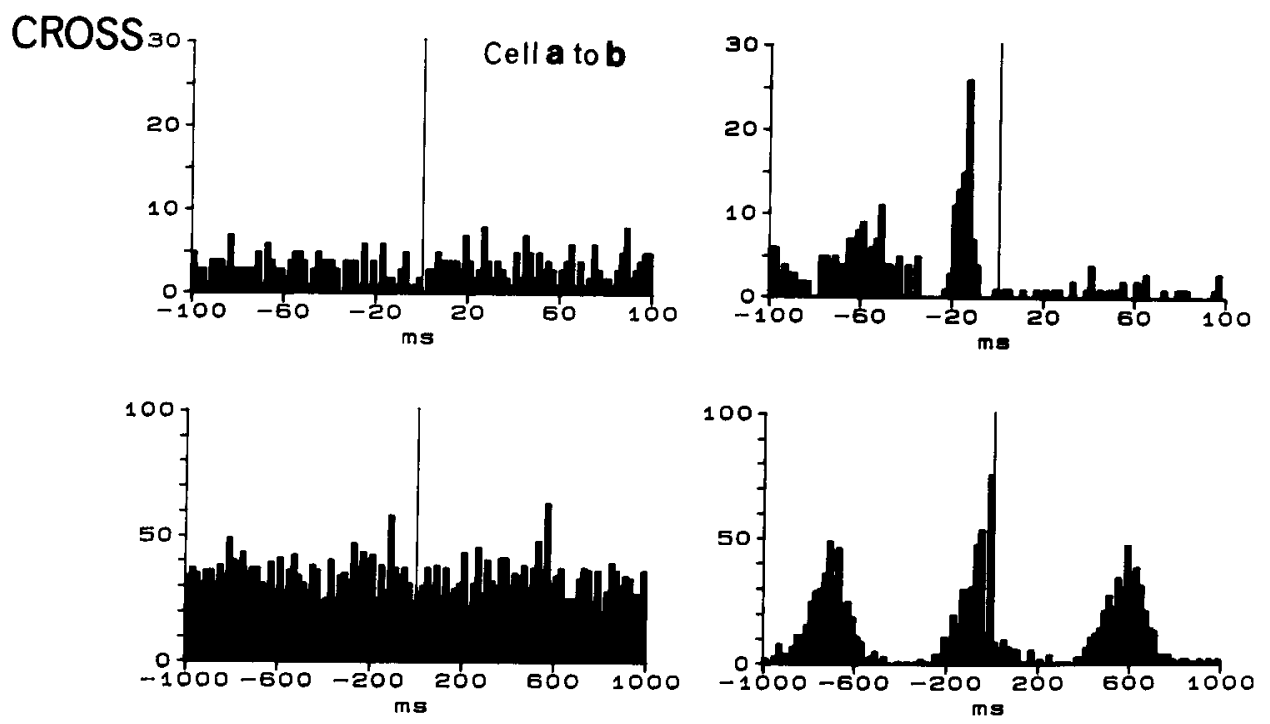

tocorrelograms showed that the rhythmicity of cell $a$, discharging spike bursts at $1.6 \mathrm{~Hz}$ before cortical stimulation, was enhanced after cortical stimulation because of reduced background noise. Cell $b$, whose flat contour in the autocorrelogram indicated absence of rhythmicity before cortical stimulation, became clearly rhythmic at $1.6 \mathrm{~Hz}$ after cortical stimuli (Fig. 9). Then, cortical stimulation led both neurons to discharge at $1.6 \mathrm{~Hz}$, with the small spike (a) in short bursts at $300 \mathrm{~Hz}$ invariably preceding by $10-20 \mathrm{msec}$ the larger spike $(b)$ occurring in trains at $30-40 \mathrm{~Hz}$ (see Figs. $8 \mathrm{C}$, 9). This self-sustained oscillation of the two synchronized neurons lasted for $25 \mathrm{sec}$ and subsequently faded.

The neuronal synchronicity was reflected in focal slow waves within the frequency of $0.5-4 \mathrm{~Hz}$. In some cases $(n=17)$, we recorded juxtacellularly large action potentials $(12-20 \mathrm{mV})$ grouped in rhythmic bursts on the crest of slow potentials presumably representing the underlying LTSs generated by the same neuron (Fig. 10A). This assumption is based on the almost unitary aspect of these potentials. Such neurons could be recorded for very long periods of time and displayed periods of oscillatory activity, interrupted by short ( $\leq 2 \mathrm{sec}$ ) or longer (5$15 \mathrm{sec}$ ) epochs of dampened oscillation (Fig. 10A). More often
( $n=32$ ), however, we recorded slow waves $(2-2.5 \mathrm{~Hz}$ ) with variable amplitudes, occasionally crowned by action potentials, presumably reflecting summated LTSs in a pool of neighbor cells (Fig. 10B).

That cortical stimulation facilitates the occurrence of $\delta$-waves on the focal thalamogram, simultaneously with the synchronization of burst firing in a group of neighbor neurons, is illustrated in Figure 11. Three stimuli to the precruciate cortex were effective in inducing a 10 sec epoch of self-sustained focal $\delta$-waves. This was accompanied by the synchronization of three simultaneously recorded LP cells, cach of them discharging highfrequency $(300-400 \mathrm{~Hz})$ spike bursts separated by $10-25 \mathrm{msec}$. Since the motor cortex does not directly project to the I.P, the most reasonable explanation of this and other similar findings is a synchronization process mediated by the conjunction properties of the RE thalamic complex, interposed in the thalamocorticothalamic loop (see Discussion).

Suppression of the slow oscillation by stimulation of brainstem cholinergic nuclei or specific afferent pathways

Rhythmic (1-4 Hz) bursts of high-frequency $(200-300 \mathrm{~Hz})$ spikes of thalamocortical cells were suppressed by short pulse trains 


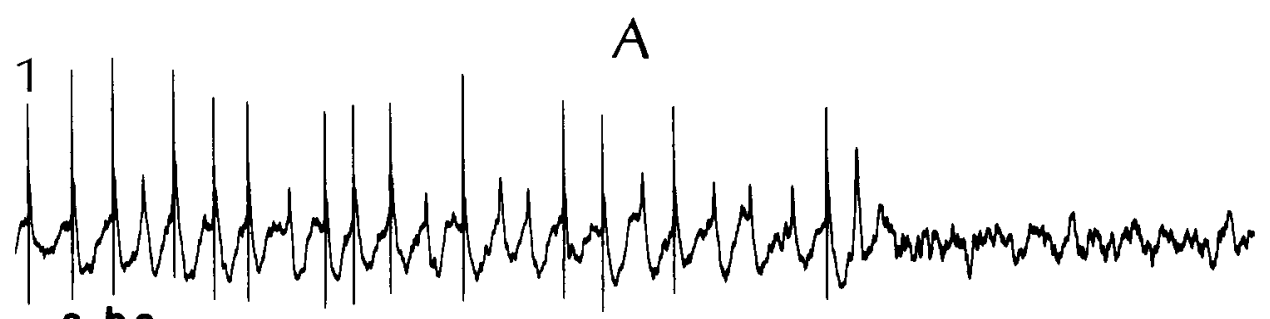

$2^{2}$ a b c

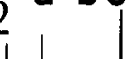

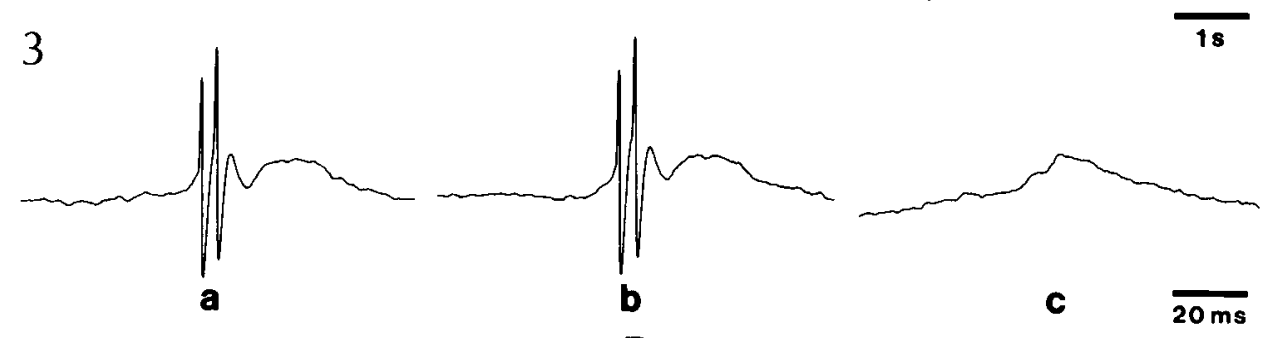

B

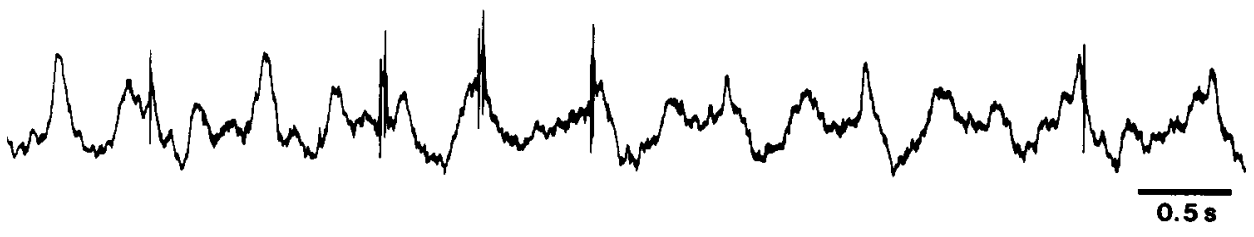

Figure 10. Focal slow waves in LP thalamic nucleus within frequency range of $2-2.5 \mathrm{~Hz} . A$, Juxtacellular recording (initially positive spike, with amplitude of $15 \mathrm{mV}$ ). Spontaneous oscillation consisted of rhythmic slow spikes, usually crowned by bursts of action potentials, but occasionally appearing in isolation (high band-pass filtered at 300 $\mathrm{Hz}$ to cut spike height and allow recording of both action potentials and slow spikes). Note periods of dampening of oscillation. Three slow spikes $(a-c)$ in 1 are expanded in 3. B. Extracellular recording of an LP unit and associated focal slow waves, probably reflecting summated LTS in a small number of neighbor elements.

in the region of PB or LDT nuclei. The suppression was usually of short duration, $\leq 5 \sec (n=29)$, and much less often $(n=6)$ lasted for $\geq 10 \mathrm{sec}$.

The short-lasting suppression of cells' slow oscillation, associated with EEG desynchronization, is shown in both neurons of Figure 12. Juxtacellular recordings of initially positive, highamplitude $(\geq 15 \mathrm{mV})$ spikes and simultaneous recording of focal slow waves showed that the stimulation of PB/LDT nuclei induced a blockage of rhythmic bursts consisting of fast action potentials, but this was not always associated with the erasure of the slow spikes. The latter, presumably reflecting LTSs extracellularly, appeared reduced in frequency after brainstem stimulation (Fig. 12B).

Figure 13 shows that various thalamocortical cells may oscillate within the frequency range of $\delta$-waves by assuming different (bursting or single-spike) discharge patterns and that they may undergo different degrees of depolarizing impingement from the PB/LDT nuclei. Both elements of the neuronal pair in Figure 13 oscillated together at $\approx 1 \mathrm{~Hz}$, with cell $a$ displaying bursts of spikes at $300 \mathrm{~Hz}$ that preceded the trains of single spikes of neuron $b$. LDT stimulation silenced the bursting neuron for 5 sec and tonically increased the firing rate of cell $b$ from $10-15$ $\mathrm{Hz}$ to $30 \mathrm{~Hz}$.

Intracellularly, the PB/LDT-induced diminution or complete blockage of the slow oscillation was accompanied by $20-30 \%$ increase in membrane conductance (Fig. 14).

A longer-lasting PB/LDT suppressing effect on the slow thalamic rhythm is shown in Figure 15, depicting the intracellular recording of an LP cell that oscillated spontaneously for tens of minutes. The $2 \mathrm{~Hz}$ oscillation consisted of LTSs, generally crowned by bursts of high-frequency spikes and followed by AHPs. Sequences of fast $(20 \mathrm{~Hz})$ depolarizing events, probably dendritic spikes, occurred on the descent of the full action potentials (see asterisk and inset in Fig. 15A) and recurred quite rhythmically every $3 \mathrm{sec}$. As a rule, these sequences of fast depolarizations reset the rhythm of the slow oscillation by delaying the next cycle (see especially before brainstem stimulation in both $A$ and $B$ ). The PB area was stimulated with one pulse train $(A)$ and, more effectively, with five short pulse trains $(B)$. The rhythmic LTSs and bursts of action potentials were dramatically reduced $(A)$ or completely obliterated $(B)$ for $12 \mathrm{sec}$ and $16 \mathrm{sec}$, respectively. In $B$, the suppression of slow oscillation was associated with a substantial membrane depolarization. All these PB effects were accompanied by blockage of high-amplitude slow EEG rhythms. Intcrestingly, the EEG rcsponsc did not take the exclusive pattern of the classical desynchronizing (flattening) reaction, which consists of suppression of cortical spindles and $\delta$-waves, but also included the clear-cut appearance of a fast, $40 \mathrm{~Hz}$ oscillation over the cortex (Fig. 15A). In a parallel study, we have demonstrated that intracellularly recorded thalamocortical cells display intrinsically as well as extrinsically generated $40 \mathrm{~Hz}$ oscillations and that $\mathrm{PB} / \mathrm{LDT}$ stimulation potentiates cortical $40 \mathrm{~Hz}$ waves, a cholinergic effect that is blocked by muscarinic antagonists (Steriade et al., 1991).

Systemic administration of the nicotinic antagonist mecamylamine suppressed the PB/LDT-induced short-term suppressing effect on thalamic $\delta$-oscillation (Fig. 16). This action was obtained in 16 neurons. The PB/LDT-induced long-lasting 

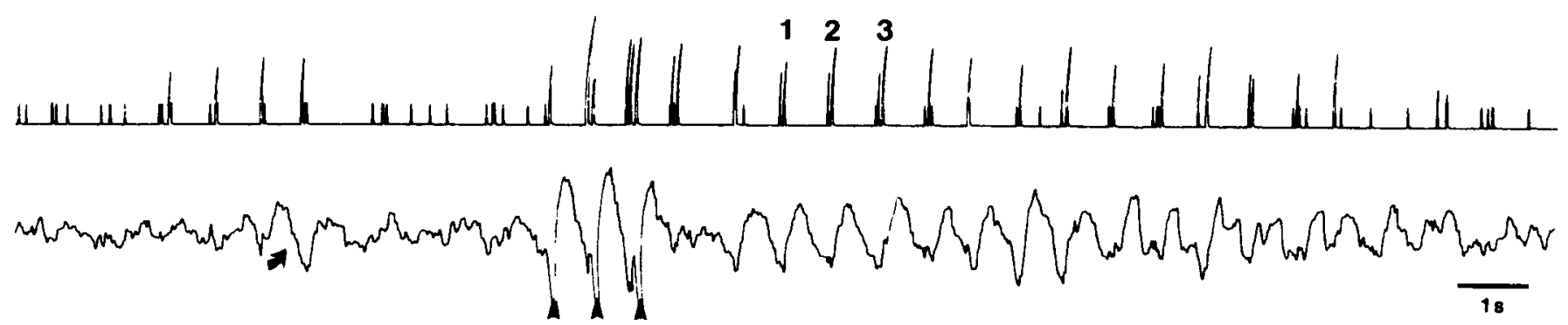

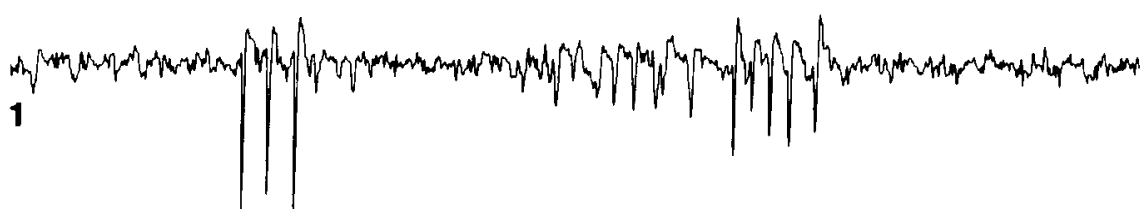
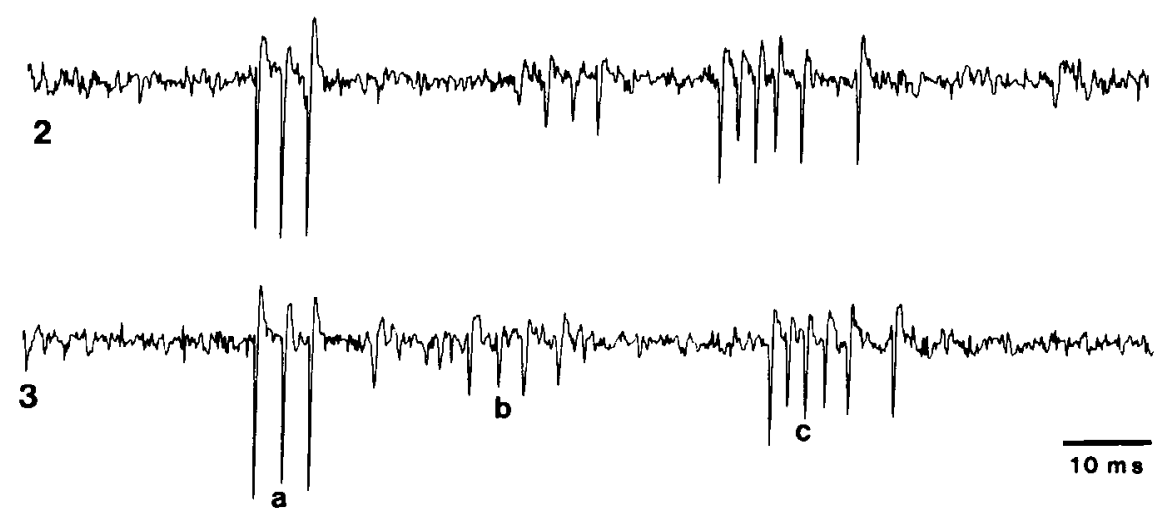

Figure 11. Cortical-induced synchronization of three cells $(a-c)$, simultaneously recorded in LP nucleus, and occurrence of focal $\delta$-waves. Top two traces, Firing of three cells (deflections exceeding the lowest level indicate spike bursts of one, two, or all three cells) and focal waves recorded by the same microelectrode. Note appearance of episodic slow waves (oblique arrow) preceded by burst firing. After three cortical stimuli (arrowheads), buildup of $\delta$-waves $(1.5 \mathrm{~Hz}$ ) lasted for $8 \mathrm{scc}$, associated with synchronous spike bursts in all three cells (epochs 1,2 , and 3 are expanded in the bottom three traces and depicted below with original spikes). Note regular sequence of high-frequency ( $300-400 \mathrm{~Hz})$ spike bursts in cells $a-c$.

suppression of slow oscillation was antagonized by scopolamine in only two extracellularly recorded neurons (data not shown; see Discussion).

That the blockage of the slow thalamic oscillation is not exclusively due to the cholinergic modulation was shown in experiments on dLG cells $(n=20)$. The $\delta$-rhythmicity $(1.6 \mathrm{~Hz})$ of their spike bursts or single spikes was suppressed by light stimulation and replaced by tonic repetitive discharges (Fig. 17).

\section{Discussion}

We have demonstrated that a slow oscillation of cortical-projecting thalamic neurons within the frequency range of EEG $\delta$-waves is potentiated, and adjacent thalamic cells are synchronized, by corticofugal volleys, whereas the same oscillation is suppressed by ascending excitatory impulses along diffusely projecting or specific afferent pathways. The issue here is that, although this oscillation is generated by an interplay of intrinsic currents in individual thalamic cells, the modulation by synaptic networks including corticothalamic and brainstem-thalamic neurons is effective (1) to induce or start again a dampened oscillation, (2) to pace conjointly otherwise independent elements, or (3) to disrupt the synchronized rhythm and replace it by tonic firing. These actions are, in fact, the basic cellular aspects of the EEG-synchronized and desynchronized behavioral states. We now discuss the neuronal mechanisms underlying the fluctuations of the slow thalamic oscillation during different states of vigilance.
The cerebral cortex facilitates the slow thalamic oscillation and synchronizes thalamic neurons

The influence of cortical cells upon the thalamus varies with their state-dependent discharge patterns. During EEG-desynchronized behavioral states (waking and REM sleep), the discharge rates of identified corticothalamic neurons increase tonically, whereas during EEG-synchronized sleep the same neurons fire short, high-frequency bursts separated by long periods of silence (Steriade, 1978). The tonic firing of cortical neurons during brain-activated states exerts a powerful depolarizing impingement upon thalamic cells, as corticothalamic axons are known to release excitatory amino acids. This action prevents the genesis of $\delta$-oscillation in the thalamus since the interplay between the intrinsic currents $\left(I_{h}\right.$ and $\left.I_{t}\right)$ generating the slow rhythm is critically dependent upon membrane hyperpolarization (see Fig. 2). By contrast, during EEG-synchronized sleep, the diminished firing rate of cortical cells, with the consequent disfacilitation of thalamic cells, creates favorable conditions for the appearance of the slow oscillation. We have observed that the propensity for spontaneous oscillations is greatly enhanced in thalamic nuclei deprived of their cortical connections or after $\mathrm{K}^{+}$-induced spreading depression in the appropriate cortical areas (Curró Dossi et al., 1991). Besides, during slow-wave sleep, high-frequency bursts in corticothalamic neurons phasically drive thalamic RE and local-circuit GABAergic elements. In turn, both these cell types are sources of long-lasting IPSPs in thalamic 


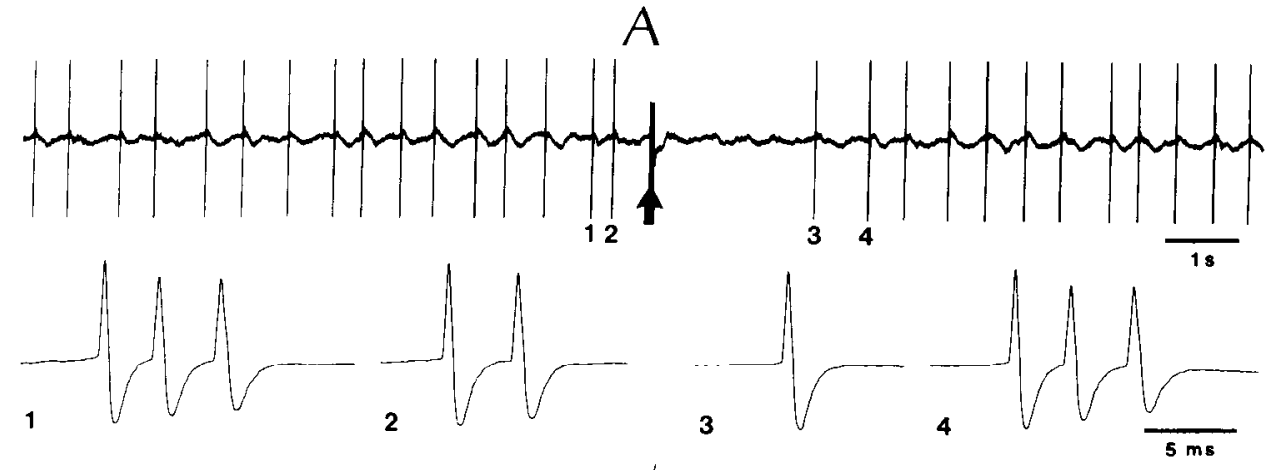

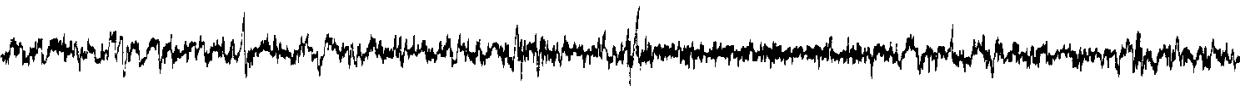

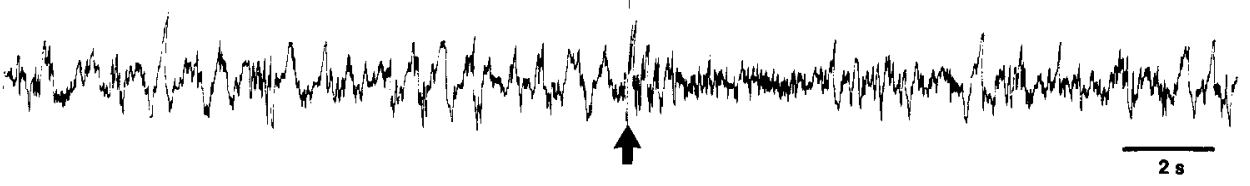

B
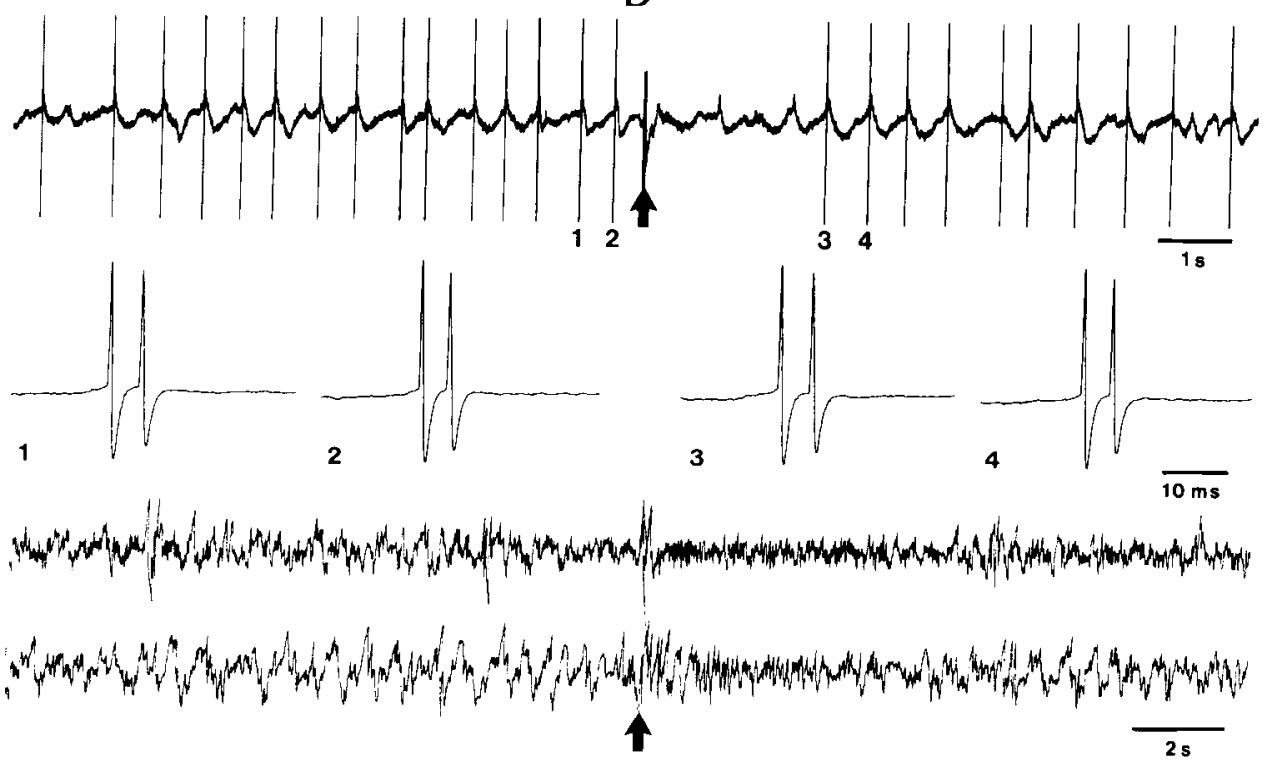

Figure 12. Stimulation of brainstem PB area blocks slow oscillation (extracellular rccordings). $A$ and $B$, Two different neurons recorded in the VA-VL complex. In both cases, PB stimulation (arrow; $0.1 \mathrm{sec}$ pulse train at $300 \mathrm{~Hz}$ ) blocked slow $(2-2.5 \mathrm{~Hz})$ oscillation consisting of spike bursts; suppression lasted for 2.5-3 sec. Two spike bursts before PB stimulation $(I, 2)$ and two after $(3,4)$ are expanded in the middle traces (in $A, 3$ is single spike). At the bottom in both $A$ and $B$, EEG traces from post- and precruciate gyri show activation responses to $\mathrm{PB}$ stimulation. relay neurons (Roy et al., 1984; Paré et al., 1991), thus setting the scene for the slow oscillation.

As to the presence of a slow oscillation in RE neurons, waves within $\delta$-frequency have been focally recorded in RE nucleus of brain-intact animals (Steriade et al., 1986) as well as in the cortical- and thalamic-deafferented RE nucleus (Steriade et al., 1987). Recent experiments in this laboratory have shown that perigeniculate and rostrolateral RE neurons display a voltagedependent oscillation at $\delta$-frequencies (Amzica et al., 1991; R. Curró Dossi, D. Contreras, and M. Steriade, unpublished observations). The presence of intrinsic slow oscillations in RE neurons would not, however, be necessary for invoking a synaptic linkage of these neurons in the route of the synchronizing action exerted by corticothalamic volleys (see Figs. 8, 9, 11). In fact, during sleep, RE cells could just transform the corticothalamic excitatory burst into an inhibitory input that, by virtue of widespread thalamic projections, would synchronize large thalamic territories within the $\delta$-frequency. Multiple-electrode recordings should be performed to detect whether or not $\delta$-waves occur simultaneously in various thalamic nuclei in the presence of RE nucleus and after lesions of RE perikarya.

The role played by the other thalamic inhibitory cell class, local interneurons, in the $1-2 \mathrm{~Hz}$ oscillation was suggested in a previous study. We showed that, after transections disconnecting dorsal thalamic nuclei from the RE nuclear complex or after chemical lesions of RE perikarya, thalamocortical cells display an all-burst discharge pattern, with a spectacular rhythmicity of spike bursts at 1-2 Hz (Steriade et al., 1985). This slow rhythm of spike bursts was interpreted as resulting from the disinhibition of GABAergic local-circuit cells after disconnection from their inputs arising in RE cells, in view of the fact it was abolished by bicuculline. The bursts at $1-2 \mathrm{~Hz}$ did not reflect a similar rhythmicity in local-circuit cells as we did not find this rhythmicity in putative interneurons. Rather, the $\mathrm{Cl}^{-}$-dependent spike bursts in RE-disconnected thalamocortical cells was ascribed to a frequency transformation phenomenon, from 10 $12 \mathrm{~Hz}$ IPSPs generated by local interneurons to $1-2 \mathrm{~Hz}$ spike bursts (Steriade et al., 1985), possibly because of the slow ki- 

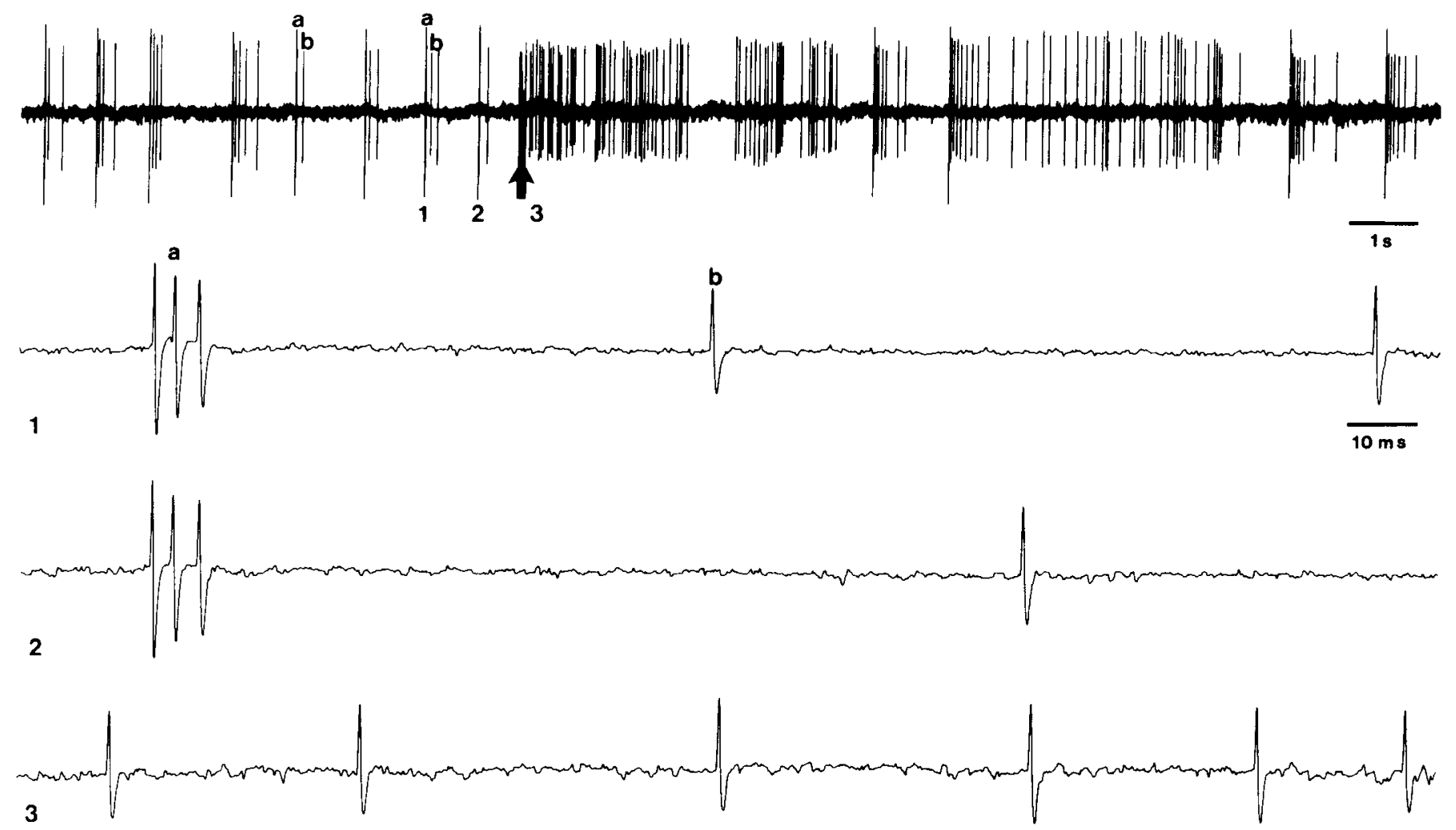

Figure 13. PB-induced blockage of slow oscillation and tonically increased firing in two simultaneously recorded cells in CL nucleus (extracellular recordings). Two cells are labeled $a$ (bursting) and $b$ (single spikes). PB stimulation (arrow) was a 0.1 sec pulse train at $300 \mathrm{~Hz}$. Periods $1-3$ indicated on the top trace are expanded in the bottom three traces.

netics of the $\mathrm{Ca}^{2+}$ channel (Carbone and Lux, 1984). While the role of RE cells may be related to the conjunction of distantly located thalamic nucleic, local-circuit cells would contribute to synchronization processes in circumscribed territories of various nuclei.

We postulate that the resonant thalamocorticothalamic loop transfers toward the cerebral cortex action potentials crowning the rhythmic LTSs of which the slow oscillation is constituted and, in turn, drives thalamic cells by backward volleys. The existence of such a reciprocal loop, involving just one interposed synapse in deep cortical layers, was suggested a long time ago (Dusser de Barenne and McCulloch, 1938; Chang, 1950) and is now substantiated by morphological data combining tracing techniques with electron microscopy (White and Hersch, 1982). We have provided evidence suggesting that inhibitory thalamic neurons are major recipients of the corticothalamic drive, since the oscillation was potentiated (Figs. 3-5) or generated (Fig. 7) on the background of the cortical-evoked hyperpolarization in thalamocortical neurons, and it could even consist of IPSPs. In the latter case (Fig. 6), the spike burst transferred to the cerebral cortex would excite cortical cells projecting to RE or local-circuit thalamic cells that would impose IPSPs back on thalamocortical cells.

In some neurons, however, the slow rhythmicity consisted of trains of action potentials (cell $b$ in Fig. 8), which did not betray an intrathalamic inhibitory input (that, in all likelihood, would have resulted in high-frequency bursts), but rather reflected an excitatory drive. The shortest lead time (10-15 msec) between cells $a$ and $b$ after their synchronization following cortical stimulation (see crosscorrelograms in Fig. 9) and the excitatory nature of the spike train in cell $b$ suggest that this coupling was probably realized by the thalamocortical transfer of $a$-burst and the subsequent corticothalamic excitation of cell $b$.

The effectiveness of corticothalamic volleys in inducing spindling (Steriade, 1984) and in facilitating the occurrence of $\delta$-rhythmicity (present results) applies to two quite different types of oscillations: the former is synaptically generated, while the latter arises from intrinsic properties of thalamic cells. Thus, cortically evoked spindles are due to the activation of the spindle pacemaker, the RE nucleus, with subsequent IPSP-rebound sequences in thalamocortical cells, whereas the potentiating cortical action on $\delta$-oscillation results from the fact that the $V_{m}$ of thalamocortical cells is about $10 \mathrm{mV}$ more negative when the $\delta$-rhythmicity occurs (see this difference in Fig. 5).

In this context, we propose that thalamocortical neurons undergo a progressive hyperpolarization from drowsiness to late stages of sleep with EEG synchronization. Our hypothesis is based on different sets of data. (1) Neurons recorded from brainstem-thalamic modulatory systems progressively decrease their firing rates from sleep onset to late sleep. This was shown for dorsal raphe, locus coeruleus, and brainstem reticular neurons (see details in Steriade and McCarley, 1990). The major transmitters of these cell types, 5-HT, noradrenaline (NA), and ACh, depolarize thalamic neurons by decreasing various $\mathrm{K}^{+}$conductances (McCormick, 1990; McCormick and Pape, 1990b). It is then expected that a progressive hyperpolarization will be installed in target thalamic cells. In fact, during the late stage of natural EEG-synchronized sleep, the $V_{m}$ of dLG cells is 7-10 $\mathrm{mV}$ more hyperpolarized than during EEG-desynchronized behavioral states (Hirsch et al., 1983). (2) The difference between $V_{m}$ at sleep onset and during late sleep would account for the prevalence of spindle oscillations and $\delta$-waves during the former 
and latter phase, respectively. We have indeed demonstrated that $\delta$-thalamic oscillations appear at a more hyperpolarized $V_{m}$ (see Figs. 5, 6). That an increased level of hyperpolarization in thalamocortical cells is associated with a switch from spindling to $\delta$-waves is also suggested by the decreased frequency of thalamic rhythms from 8 to $2 \mathrm{~Hz}$ after systemic administration or thalamic microinjection of NMDA blockers (Buzsáki, 1991). All the above evidence indicates that, as the state of sleep deepens and the firing of cortical cells decreases, the thalamus passes from spindles to $\delta$-oscillations on the background of an increased $V_{m}$ hyperpolarization. (3) Lastly, in a parallel intracellular study (Nuñez et al., 1991), we explained the classical clinical observation that $\delta$-rhythms are rarely seen during the early stage of sleep when spindle oscillations prevail by the fact that spontaneous or cortical-induced cyclic IPSPs, constituting spindle sequences, drastically cut off or prevent the occurrence of the 0.5$4 \mathrm{~Hz}$ oscillation when the latter was recorded at the upper limit of its voltage range.

\section{Mesopontine cholinergic nuclei prevent the slow oscillation}

The suppression of the $\delta$-thalamic oscillation and the decoupling of synchronized thalamic neurons by stimulating brainstem PB/ LDT nuclei (Figs. 12,13) by no means imply that the ascending cholinergic system is the only one to prevent the occurrence of this rhythm. McCormick and Pape (1990b) have reported that in vitro administration of 5-HT or NA agonists results in a dampening of the slow oscillation and a replacement of it by depolarization of dLG thalamic cells. This effect changed the rhythmic spike bursts into the repetitive, single-spike discharge mode characteristic for arousal. Similar effects are expected to be elicited by $\mathrm{ACh}$ in view of the present results and of in vitro data demonstrating the ACh-induced depolarization of cat dLG neurons (McCormick and Prince, 1987).

Our choice to investigate the modulatory effects of the brainstem-thalamic cholinergic system is justified by the fact that sleep $\delta$-waves are blocked not only upon awakening, but also with transition to the other EEG-desynchronized state, REM sleep. While brainstem-thalamic cholinergic neurons discharge at high rates during both waking and REM sleep and their increased activity precedes by $30-60 \mathrm{sec}$ the most precocious signs of EEG activation during transition from EEG-synchronized slecp to either arousal or REM sleep (Steriade et al., 1990a), monoamine-containing neurons are virtually silent during REM sleep (Hobson et al., 1975; McGinty and Harper, 1976; AstonJones and Bloom, 1981; Lydic et al., 1987). Then, although cholinergic and monoaminergic neurons do conjointly act during wakefulness, the tonic discharge mode and enhanced excitability of thalamic and cortical neurons during REM sleep are under the activating control of brainstem and nucleus basalis (NB) cholinergic neurons.

The relatively short duration of the PB/LDT-induced suppression of the slow oscillation, the associated increased membrane conductance, and the sensitivity to nicotinic antagonists all indicate that this effect has features similar to those characterizing the short-lasting nicotinic depolarizing responses of thalamocortical cells (Hu et al., 1989; Curró Dossi et al., 1991). That the majority of neurons displayed in the present study this type of response is probably due to the fact that the muscarinicmediated depolarizing response is voltage dependent, being depressed and eventually disappearing under steady hyperpolarization (Curró Dossi et al., 1991), while the occurrence of the slow oscillation is critically dependent upon hyperpolarization

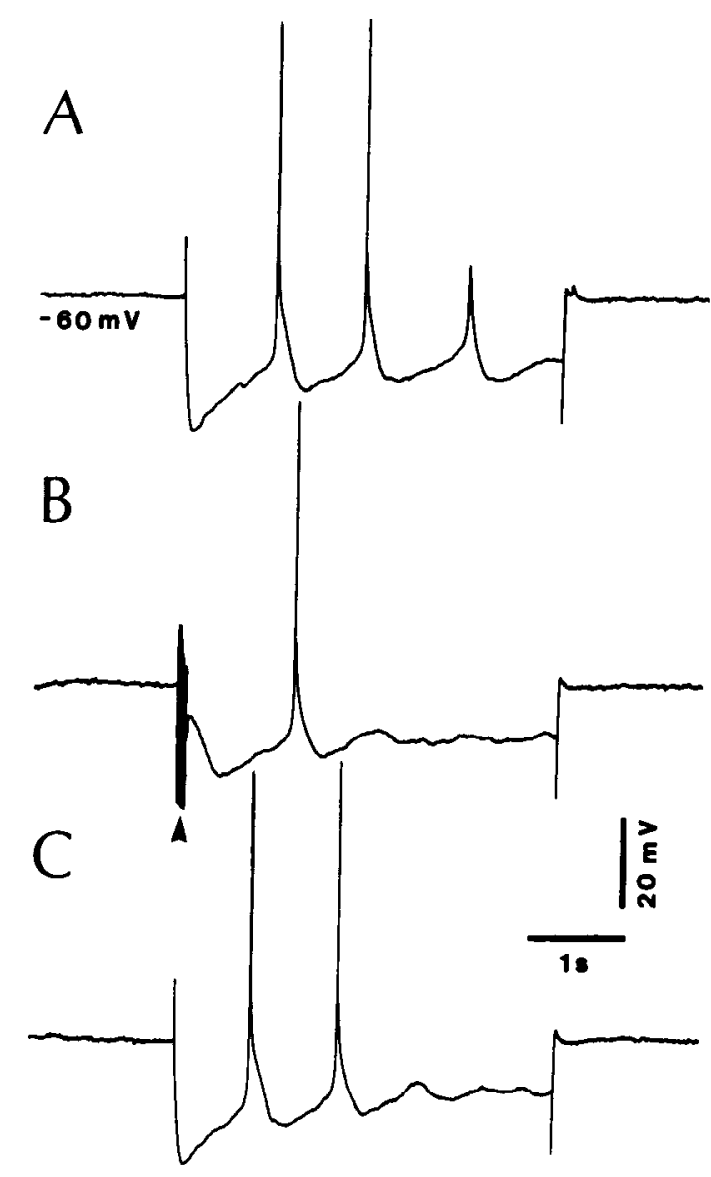

Figure 14. PB-induced blockage of slow oscillation is associated with increased membrane conductance (CL thalamocortical cell). $A$, Hyperpolarizing current pulse $(1.3 \mathrm{nA})$ elicited $1 \mathrm{~Hz}$ oscillation. $B$, PB pulse train (arrowhead; delivered simultaneously with onset of hyperpolarizing pulse) induced increased membrane conductance and reduced oscillation. $C$, Recovery of hyperpolarization-activated oscillation after PB stimulation.

(see Fig. 2). In some cases, however, long-lasting (12-16 sec) suppression of the slow oscillation was observed (see Fig. 15), and scopolamine was required to block the PB/LDT-induced effect completely. We should emphasize that the cffccts of stimulating PB/LDT nuclei may not be exclusively due to the release of $\mathrm{ACh}$. In those cases in which we failed to block completely the PB/LDT-induced suppression of thalamic slow oscillation by using cholinergic antagonists, we hypothesize that this was due to the colocalization of $\mathrm{ACh}$ with excitatory amino acids in mesopontine cholinergic neurons (B. E. Jones, personal communication). In support of this assumption, the present results indicated that blockage of slow rhythmic bursting in dLG cells occurs during light stimulation (Fig. 17). We may then generalize that any, diffusely projecting or specific sensory, system that is able to depolarize thalamic cells can obliterate their $\delta$-rhythmicity.

The similarity between the ACh suppressing action on $\delta$-waves generated in the thalamus and cerebral cortex has to be emphasized. As in the present study, in which brainstem cholinergic projections were shown to obliterate $\delta$-oscillation in the thalamus, NB cholinergic projections do effectively counteract $\delta$-genesis in the cerebral cortex. This is ascertained by data showing that (1) NB stimulation results in ACh release in the neocortex (Casamenti et al., 1986), (2) excitotoxic lesions of NB perikarya 

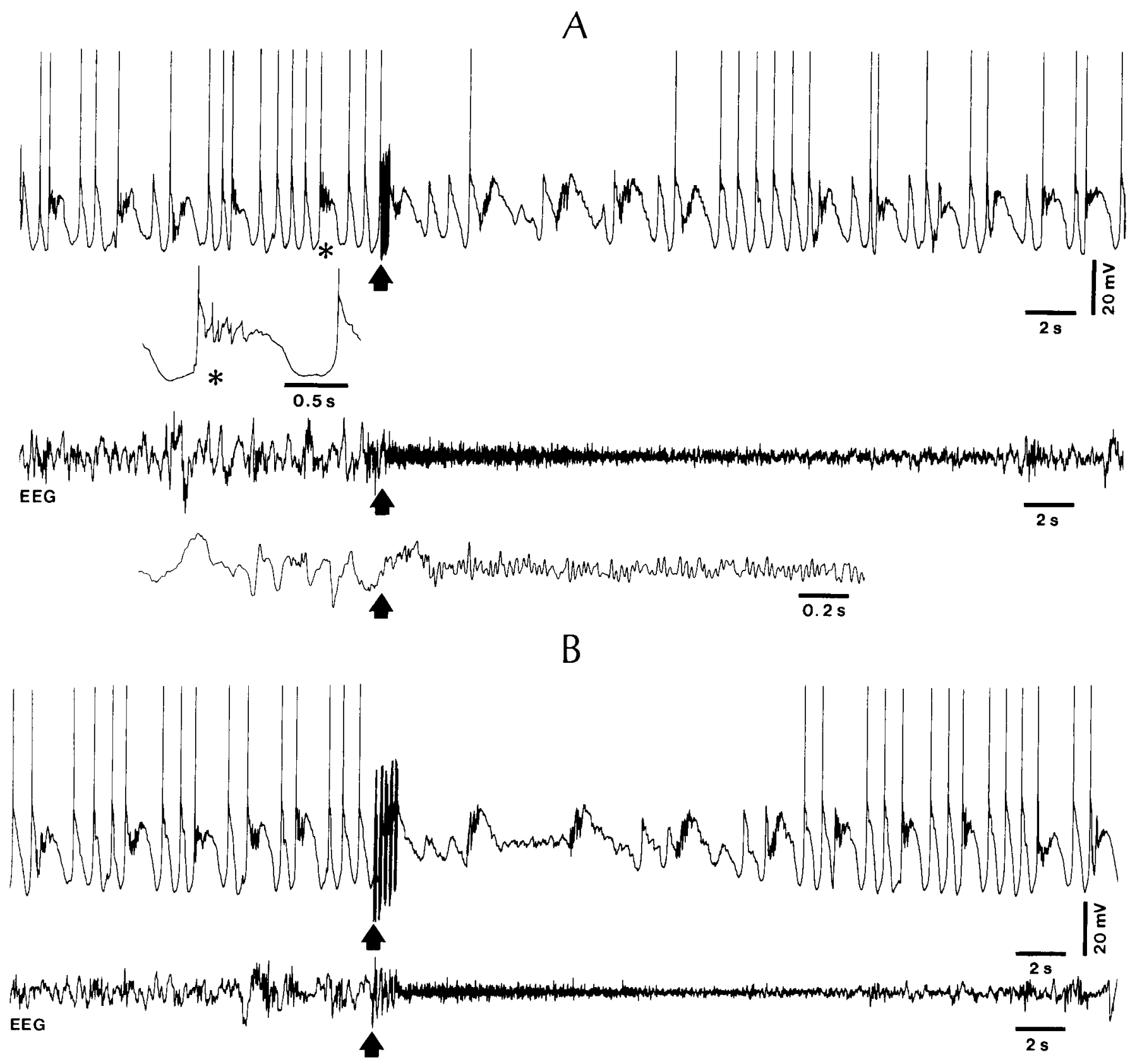

Figure 15. Intracellularly recorded slow oscillation in LP cell and its suppression by PB stimulation (one and five pulse trains in $A$ and $B$, respectively; see details in text). Below the top (intracellular) trace, $E E G$ recording from the postcruciate gyrus (in $A$, an expanded epoch of EEG trace around the PB pulse train is also depicted to show the $40 \mathrm{~Hz}$ oscillation induced by PB stimulation; see text). A sequence of fast depolarizing events in $A$ (asterisk) is expanded and shown below. Full explanation is given in text.

are followed by decrease in ChAT (Pepeu et al., 1990) and increase in $\delta$-power over the ipsilateral cortical areas (Buzsáki et al., 1988b), and (3) both EEG-desynchronized states of waking and REM sleep are associated with markedly increased ACh output from the cortex (Celesia and Jasper, 1966; Jasper and Tessier, 1971). In the cercbral cortex, there is no systematic analysis of $\delta$-waves at the intracellular level. The silenced firing of units simultaneously recorded from different cortical layers during the positive phase of $\delta$-waves (see Steriade and Buzsáki, 1990, their Fig. 1.21) was attributed, in addition to IPSPs, to summation of long-lasting AHPs in layer V pyramidal cells (Buzsáki et al., 1988a). Medium and slow AHPs in cat senso- rimotor cortex, whose duration and sensitivity to muscarinic agonists would fit with their involvement in the genesis of $\delta$-waves, are due to a family of $\mathrm{K}^{+}$conductances, including a $g_{\text {K(Ca) }}$ (Schwindt et al., 1988a,b). The suppressing action of ACh, as well as 5-HT and NA, on $g_{\mathrm{K}(\mathrm{Ca})}$ is now established even in human cortical cells (McCormick and Williamson, 1989).

\section{Concluding remarks}

Until quite recently, the oscillatory mode of the thalamus was exclusively defined by spindle oscillations generated in a synaptic network including RE neurons (Steriade et al., 1990c). The other sleep rhythm, consisting of $\delta$-waves, was commonly thought 


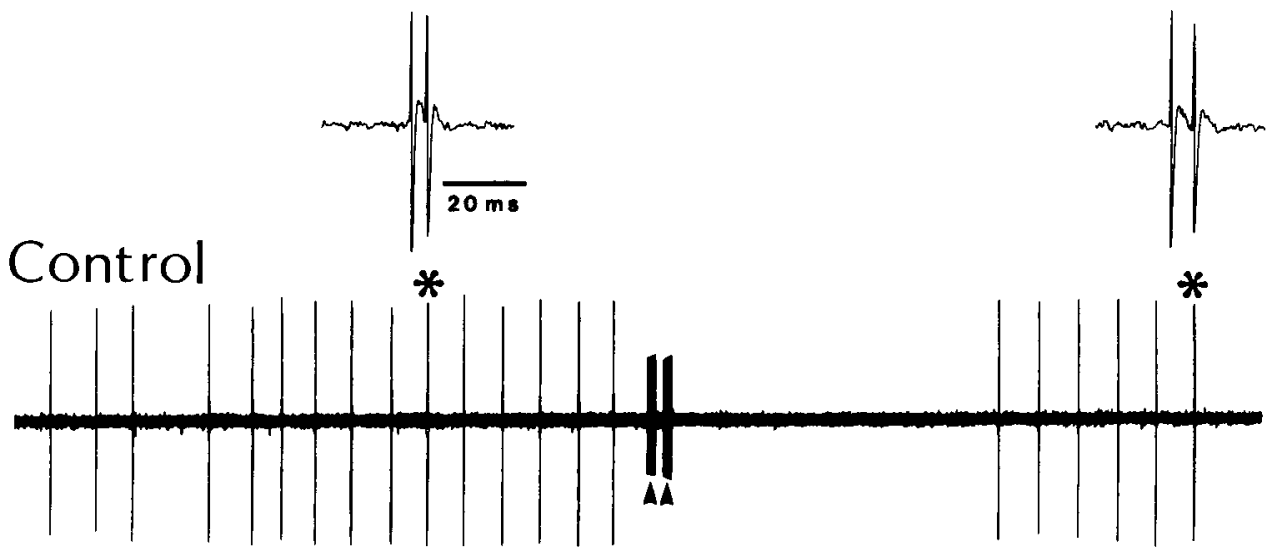

Mecamylamine

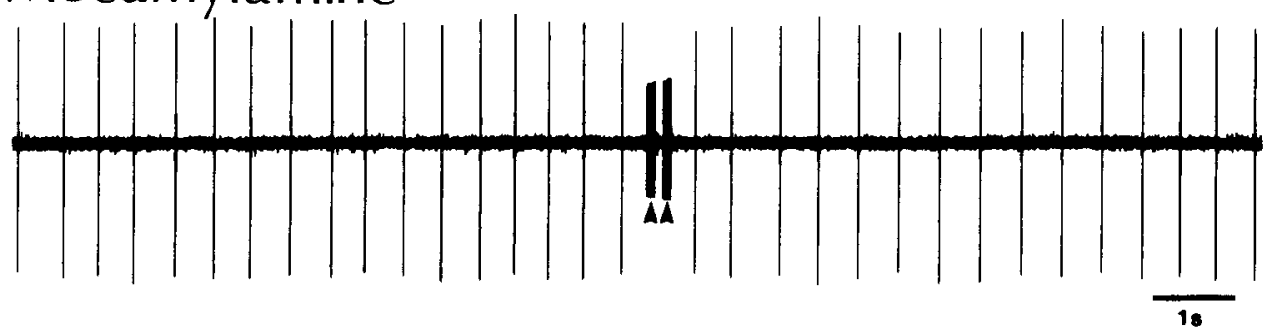

Figure 16. PB-induced blockage of slow oscillation is antagonized by mecamylamine $(40 \mu \mathrm{g} / \mathrm{kg}$, i.v.; CL thalamocortical cell). Control, Oscillation (2 $\mathrm{Hz}$ ) consisting of spike bursts (two bursts indicated by asterisks are expanded above) was suppressed for 4 sec by two shock trains to the PB area (arrowheads). Mecamylamine antagonized the PB effect.

to originate in the cerebral cortex. In vitro (Leresche et al., 1990; McCormick and Pape, 1990a) and in vivo (Curró Dossi et al., 1991) studies have demonstrated that thalamocortical cells are also able to display oscillations within the frequency range of $\delta$-waves $(0.5-4 \mathrm{~Hz})$ because of an interplay of intrinsic currents at $V_{m}$ more negative than $-65 \mathrm{mV}$, that is, the voltage range reached by thalamic cells during natural EEG-synchronized sleep. Since during both spindle and $\delta$-oscillations thalamocortical cells are hyperpolarized, these oscillations are associated with a low transfer function that is a prerequisite for forebrain deafferen- tation from the outside world. The present demonstration that cortical volleys potentiate thalamic $\delta$-oscillations and synchronize thalamic neurons in this frequency suggests that, during late stages of natural sleep, the appearance of this slow rhythm with all its plenitude depends on impulse reverberation along resonating thalamocortical loops. Future investigations should elucidate whether RE and/or local-circuit inhibitory neurons display this oscillation and which is the role of these GABAergic cell classes in setting the cortical-elicited hyperpolarization leading to $\delta$-oscillation.

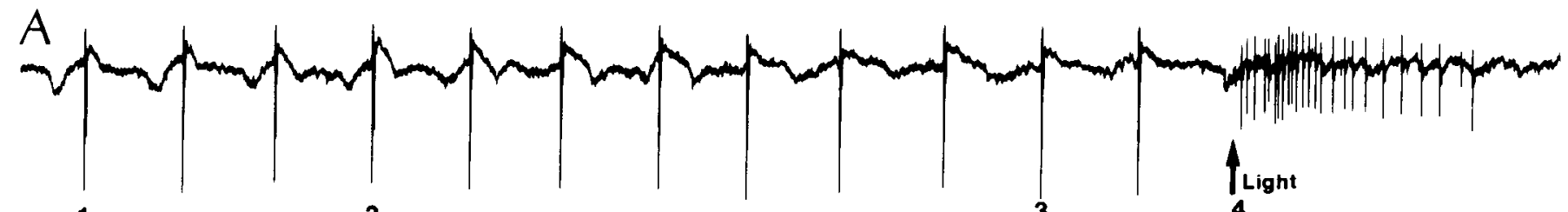

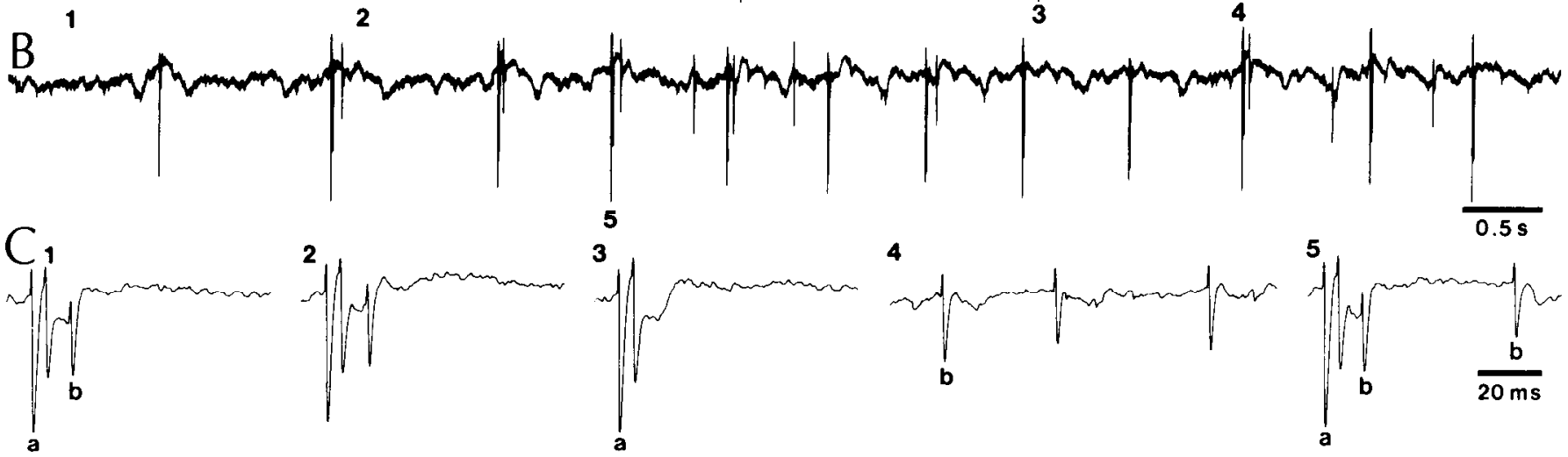

Figure 17. Suppression of slow $(1.8 \mathrm{~Hz})$ oscillation of dLG thalamic cells by light stimulation. Extracellular recordings of two neurons. Epochs numbered $1-5$ in $A$ and $B$ arc expanded in $C$. Cell $a$ (large spike) discharged a burst of two, 4 msec-delayed spikes. Cell $b$ discharged single spikes, $10-12 \mathrm{msec}$ after cell $a$. $A$, Light stimulation suppressed bursts of cell $a$ and induced tonic firing in cell $b$. $B$, Recovery of slow oscillation after light off. 


\section{References}

Amzica F, Nuñez A, Steriade M (1991) Delta oscillations in perigeniculate (reticular) thalamic neurons. Soc Neurosci Abstr 17: in press.

Aston-Jones G, Bloom FE (1981) Activity of norepinephrine-containing locus coeruleus neurons in behaving rats anticipates fluctuations in the sleep-waking cycle. J Neurosci 1:876-886.

Buzsáki G (1991) The thalamic clock: emergent network properties. Neuroscience 41:351-364.

Buzsáki G, Bickford RG, Armstrong DM, Ponomareff G, Chen KS, Ruiz R, Thal LJ, Gage FH (1988a) Electrical activity in the neocortex of freely moving young and aged rats. Neuroscience 26:735744.

Buzsáki G, Bickford RG, Ponomareff G, Thal LJ, Mandel R, Gage FH (1988b) Nucleus basalis and thalamic control of neocortical activity in the freely moving rat. J Neurosci 8:4007-4026.

Carbone E, Lux HD (1984) A low-voltage-activated fully inactivating $\mathrm{Ca}$ channel in vertebrate sensory neurones. Nature 310:501-502.

Casamenti F, Defenu G, Abbamondi AL, Pepeu G (1986) Changes in cortical acetylcholine output induced by modulation of the nucleus basalis. Brain Res Bull 16:689-695.

Celesia GG, Jasper HH (1966) Acetylcholine released from cerebral cortex in relation to state of activation. Neurology (Minn) 16:10531064.

Chang HT (1950) The repetitive discharges of corticothalamic reverberating circuit. J Neurophysiol 13:235-257.

Curró Dossi R, Paré D, Steriade M (1990) Short-lasting nicotinic and long-lasting muscarinic depolarizing responses of thalamocortical neurons to stimulation of mesopontine cholinergic nuclei. J Neurophysiol 65:393-406.

Curró Dossi R, Nuñez A, Steriade M (1991) Electrophysiology of a slow $(0.5-4 \mathrm{~Hz})$ intrinsic oscillation in thalamocortical cells of cat in vivo. J Physiol (Lond), in press.

Deschênes M, Paradis M, Roy JP, Steriade M (1984) Electrophysiolugy of neurons of lateral thalamic nuclei in cat: resting properties and burst discharges. J Neurophysiol 51:1196-1219.

Dusser de Barenne JG, McCulloch WS (1938) The direct functional interrelation of sensory cortex and optic thalamus. J Neurophysiol $\mathbf{I}$ : 176-186.

Eysel UT, Pape HC, Van Schayck R (1986) Excitatory and differential disinhibitory actions of acetylcholine in the lateral geniculate nucleus of the cat. J Physiol (Lond) 370:233-254.

Hirsch JC, Fourment A, Marc ME (1983) Sleep-related variations of membrane potential in the lateral geniculate neurons in vitro. Brain Res 259:308-312.

Hobson JA, McCarley RW, Wyzinski PW (1975) Sleep cycle oscillation: reciprocal discharge by two brain stem neuronal groups. Science 189:55-58.

Hu B, Steriade M, Deschenes M (1989) The effects of brainstem peribrachial stimulation on neurons of the lateral geniculate nucleus. Neuroscience 31:13-24.

Jahnsen H, Llinás R (1984a) Electrophysiological properties of guineapig thalamic neurones: an in vitro study. J Physiol (Lond) 349:205226 .

Jahnsen H, Llinás R (1984b) Ionic basis for the electroresponsiveness and oscillatory properties of guinea-pig thalamic neurones in vitro. J Physiol (Lond) 349:227-247.

Jasper HH, Tessier J (1971) Acetylcholine liberation from cerebral cortex during paradoxical (REM) sleep. Science 172:601-602.

Jones EG (1985) The thalamus. New York: Plenum.

Leresche N, Jassik-Gerschenfeld D, Haby M, Soltesz I, Crunelli V (1990) Pacemaker-like and other types of spontaneous membrane potential oscillations of thalamocortical cells. Neurosci Lett 113:72-77.

Lydic R, McCarley RW, Hobson JA (1987) Serotonin neurons and sleep. II. Time course of dorsal raphe discharge, PGO waves, and behavioral states. Arch Ital Biol 126:1-28.

McCormick DA (1990) Cellular mechanisms of cholinergic control of neocortical and thalamic neuronal excitability. In: Brain cholinergic systems (Steriade M, Biesold D, eds), pp 236-264. New York: Oxford UP.

McCormick DA, Pape HC (1990a) Properties of a hyperpolarizationactivated cation current and its role in rhythmic oscillation in thalamic relay neurones. J Physiol (Lond) 431:291-318.

McCormick DA, Pape HC (1990b) Noradrenergic and serotonergic modulation of a hyperpolarization-activated cation current in thalamic relay neurones. J Physiol (Lond) 431:319-342.

McCormick DA, Prince DA (1987) Actions of acetylcholine in the guinea pig and cat medial and lateral geniculate nuclei. J Physiol (Lond) 392:147-165.

McCormick DA, Williamson A (1989) Convergence and divergence of neurotransmitter action in human cerebral cortex. Proc Natl Acad Sci USA 86:8098-8102.

McGinty DJ, Harper RM (1976) Dorsal raphe neurons: depression of firing during sleep in cats. Brain Res 101:569-575.

Morison RS, Bassett DL (1945) Electrical activity of the thalamus and basal ganglia in decorticate cats. J Neurophysiol 8:309-314.

Nuñez A, Curró Dossi R, Steriade M (1991) Spindle oscillations prevent delta oscillations in intracellularly recorded thalamocortical cells of cat. Soc Neurosci Abstr 17: in press.

Paré D, Curró Dossi R, Steriade M (1991) Three types of inhibitory postsynaptic potentials generated by interneurons in the anterior thalamic complex of cat. J Neurophysiol, in press.

Pepeu G, Di Patre PL, Casamenti F (1990) Spontaneous and drugstimulated recovery of cortical cholinergic function after lesion of the nucleus basalis. In: Brain cholinergic systems (Steriade M, Biesold D, eds), pp 358-363. New York: Oxford UP.

Roy JP, Clercq M, Steriade M, Deschênes M (1984) Electrophysiology of neurons of lateral thalamic nuclei in the cat: mechanisms of longlasting hyperpolarizations. J Neurophysiol 51:1220-1235.

Schwindt PC, Spain WJ, Foehring RC, Stafstrom CE, Chubb MC, Crill WE (1988a) Multiple potassium conductances and their functions in neurons from cat sensorimotor cortex in vitro. J Neurophysiol 59: 424-449.

Schwindt PC, Spain WJ, Foehring RC, Chubb MC, Crill WE (1988b) Slow conductances in neurons from cat sensorimotor cortex in vitro and their role in slow excitability changes. J Neurophysiol 59:450 467.

Steriade M (1978) Cortical long-axoned cells and putative interneurons during the sleep-waking cycle. Behav Brain Sci 1:465-514.

Steriade M (1984) The excitatory-inhibitory response sequence of thalamic and neocortical cells: state-related changes and regulatory systems. In: Dynamic aspects of neocortical function (Edelman GM, Gall WE, Cowan WM, eds), pp 107-157. New York: Wiley.

Steriade M, Buzsáki G (1990) Parallel activation of thalamic and cortical neurons by brainstem and basal forebrain cholinergic systems. In: Brain cholinergic systems (Steriade M, Biesold D, eds), pp 3-62. New York: Oxford UP.

Steriade M, McCarley RW (1990) Brainstem control of wakefulness and sleep. New York: Plenum.

Steriade M, Apostol V, Oakson G (1971) Control of unitary activities in cerebellothalamic pathway during wakefulness and synchronized sleep. J Neurophysiol 34:384-413.

Steriade M, Parent A, Hada J (1984) Thalamic projections of nucleus reticularis thalami of cat: a study using retrograde transport of horseradish peroxidase and fluorescent tracers. J Comp Neurol 229:531547.

Steriade M, Deschênes M, Domich L, Mulle C (1985) Abolition of spindle oscillations in thalamic neurons disconnected from nucleus reticularis thalami. J Neurophysiol 54:1473-1497.

Steriade M, Domich L, Oakson G (1986) Reticularis thalami neurons revisited: activity changes during shifts in states of vigilance. J Neurosci 6:68-81.

Steriade M, Domich L, Oakson G, Deschênes M (1987) The deafferented reticularis thalami nucleus generates spindle rhythmicity. J Neurophysiol 57:260-273.

Steriade M, Datta S, Paré D, Oakson G, Curró Dossi R (1990a) Neuronal activities in brain-stem cholinergic nuclei related to tonic activation processes in thalamocortical systems. J Neurosci 10:25412559.

Steriade M, Gloor P, Llinás RR, Lopes da Silva FH, Mesulam MM (1990b) Basic mechanisms of cerebral rhythmic activities. Electroencephalogr Clin Neurophysiol 76:481-508.

Steriade M, Jones EG, Llinás RR (1990c) Thalamic oscillations and signaling. New York: Wiley.

Steriade M, Curró Dossi R, Paré D, Oakson G (1991) Fast oscillations $(20-40 \mathrm{~Hz})$ in thalamocortical systems and their potentiation by me- 
sopontine cholinergic nuclei in the cat. Proc Natl Acad Sci USA 88 : $4396-4400$.

Villablanca J (1974) Role of the thalamus in sleep control: sleepwakefulness studies in chronic diencephalic and athalamic cats. In: Basic sleep mechanisms (Petre-Quadens O, Schlag J, eds), pp 51-81. New York: Academic.
White EL, Hersch SM (1982) A quantitative study of thalamocortical and other synapses involving the apical dendrites of corticothalamic projection cells in mouse SmI cortex. J Neurocytol 11:137-157. 